\title{
Analyzing consolidation data to obtain elastic viscoplastic parameters of clay
}

\author{
Thu M. Le ${ }^{1}$, Behzad Fatahi ${ }^{* 1}$, Mahdi Disfani ${ }^{2}$ and Hadi Khabbaz ${ }^{1}$ \\ ${ }^{1}$ Centre for Built Infrastructure Research, School of Civil and Environmental Engineering, \\ University of Technology Sydney (UTS), Sydney, 15 Broadway, Ultimo NSW 2007 Australia \\ ${ }^{2}$ Melbourne School of Engineering, The University of Melbourne, Parkville, VIC, 3010, Australia
}

(Received June 12, 2014, Revised September 15, 2014, Accepted January 13, 2015)

\begin{abstract}
A nonlinear creep function incorporated into the elastic visco-plastic model may describe the long-term soil deformation more accurately. However, by applying the conventional procedure, there are challenges to determine the model parameters due to limitation of suitable data points. This paper presents a numerical solution to obtain several parameters simultaneously for a nonlinear elastic visco-plastic (EVP) model using the available consolidation data. The finite difference scheme using the Crank-Nicolson procedure is applied to solve a set of coupled partial differential equations of the time dependent strain and pore water pressure dissipation. The model parameters are determined by applying the algorithm of trust-region reflective optimisation in conjunction with the finite difference solution. The proposed method utilises all available consolidation data during dissipation of the excess pore water pressure to determine the required model parameters. Moreover, the reference time in the elastic visco-plastic model can readily be adopted as a unit of time; denoting creep is included in the numerical predictions explicitly from the very first time steps. In this paper, the settlement predictions of thick soft clay layers are presented and discussed to evaluate and compare the accuracy and reliability of the proposed method against the graphical procedure to obtain the model parameters. In addition, comparison of the available experimental results to the numerical predictions confirms the accuracy of the numerical procedure.
\end{abstract}

Keywords: elastic viscoplastic, finite difference solution, creep, soft soils

\section{Introduction}

Soft soil creep has been considered one of the thought-provoking research topics in geotechnical engineering for the last few decades (e.g., Bjerrum 1967, Berre and Iversen 1972, Mesri et al. 1981, Yin and Graham 1996, Fatahi et al. 2012, Karim and Gnanendran 2014, Azari et al. 2014, Le et al. 2015). Several mechanisms have been proposed by different researchers, which can be classified into five categories (a) the breakdown of the inter-particle bonds in the soil structure; (b) the sliding between particles; (c) water flows in two systems; (d) deformation due to structural viscosity; and (e) the deformation due to the jumping of molecule bonds (Le et al. 2012). In microscopic scale, creep deformation results from the viscous flow of the micropore water within the microstructure of soils due to the complex electro-chemical properties of mineralogy of clay. According to Guven (1992), water system absorbed within microstructure of clay is formed

*Corresponding author, Ph.D., CPEng, E-mail: behzad.fatahi@uts.edu.au 
by three types which are: (i) the water adsorbed on the internal surfaces of clay mineral; (ii) the water layer held between clay minerals (double layer water); and (iii) the capillary water held in pores between the clay particles. The viscosity is imposed by the absorbed water layer around particles, and may induce the plastic resistance against the relative movement between the clay particles. The soil cementation and it degradation may be other factors influencing the stress-strain behaviour of soils (Nguyen et al. 2014). Creep compression may be a result of the deformation of clay clusters or microstructure units due to the flow of viscous water (Bjerrum 1967, Graham and Yin 2001, Terzaghi 1941). In term of macroscopic view, creep is due to the soil structural rearrangement or adjustment to reach a new equilibrium state under an applied stress. While visco-plastic and large strain properties of soil significantly influence the post construction behaviour of structures, the wave propagation and small strain characteristics also affect the performance of superstructures built on the soft soil under extreme loads such as earthquake (Fatahi and Tabatabaiefar 2014, Hokmabadi et al. 2014, Tabatabaiefar et al. 2012, 2013). It should be noted that the time-dependent behaviour of soft soil is not only limited to the fully saturated soft soils; for example Ho et al. (2014) studied the time dependent settlement of unsaturated soils.

After conducting a wide range of research on creep, it is widely accepted that creep is a deformation process occurring concurrently with the excess pore water pressure dissipation (Bjerrum 1967, Degago et al. 2009, Watabe et al. 2012). It can be noted that two hypotheses known as Hypotheses A and B were proposed to consider the effect of creep on settlement predictions of soils (Jamiolkowski et al. 1985). The main difference between Hypotheses A and B is related to the effect of the sample thickness on the void ratio (strain) at the end of traditional primary consolidation stage. Hypothesis B considers that the void ratio (or strain) at the end of primary consolidation is influenced by the soil layer thickness or the drainage conditions, while Hypothesis A assumes the end of primary consolidation void ratio is unique and not a function of soil thickness. For the sake of simplicity, practising engineers may compute the creep settlement based on the linear relationship between the creep compressions with logarithm of time. However, the long-term relationship between strain and logarithm of time is not necessary linear based on the field observation and laboratory measurements (Berre and Iversen 1972; Leroueil et al. 1985; Yin 1999).

Yin (1999) proposed a nonlinear creep function to substitute for the linear creep function in an attempt to describe the long-term settlement of soft soils more accurately. The nonlinear creep function developed by Yin (1999), includes a creep strain limit $\left(\varepsilon_{l m}^{v p}\right)$, initial creep coefficient $\left(y_{o}{ }_{o}\right)$ at equivalent time, $t_{e}=0$, and a time parameter $t_{o}$. Yin (1999) presented a set of long term oedometer test results of Hong Kong marine deposit and proposed a systematic curve fitting procedure to obtain the non-linear creep function parameters which is referred to as Yin (1999) approach in this paper. However, longer test durations are required to obtain more data points after the end of the primary consolidation for the creep properties including $y^{\prime}{ }_{o}$ and $\varepsilon_{l m}^{v p}$ of the non-linear creep function. Yin (1999) suggested the minimum duration of the test to be one week to obtain more accurate predictions. In addition, this method cannot be used to back-calculate the model parameters from field measurements, as compression data during the dissipation of excess pore water pressure are not adopted to determine visco-plastic parameters.

However, the non-linear creep function has a limitation regarding the model determination process. In this model, it was suggested to adopt the value of time at the end of primary consolidation $\left(t_{E O P}\right)$ as $t_{o}$ in advance. Based on the non-linear creep function and the definition of the reference time-line, $t_{o}$ is considered as the time value of the reference time-line which represents the elastic-plastic behaviour of soils without viscous strain. Thus, the reference 
time-line may include viscous strains if $t_{o}$ is adopted to be equal to $t_{E O P}$. Moreover, the values of $t_{E O P}$ may vary not just with the thickness of the soils, but also with the magnitude of the stress increments in case of multiple loading stages. The selection of $t_{E O P}$ for $t_{o}$ influences the determination of other parameters including the slope of the reference time-line $(\lambda / V)$ (which represents to the elastic-plastic behaviour of soft soil) as well as the creep parameters according to the procedure proposed by Yin (1999).

In brief, numerical optimisation methods to obtain single or several model parameters have been applied widely in other types of materials such as metals (e.g., Cooreman et al. 2007, Yun and Shang 2011), while it has been rarely employed to estimate soil parameters. This paper presents a new method to overcome the limitation of the procedure in determining the model parameters. The developed method implements an advanced optimisation method and the finite difference solution for the elastic visco-plastic model. This method can utilise all the consolidation data from the beginning to the end of the loading stages in order to increase the number data points to be used for the model parameter determination. The prediction of the settlement during the dissipation of the excess pore water pressure can be improved due to the utilisation of the consolidation data during the dissipation process. Several loading stages are involved in the optimisation process simultaneously. Thus, the optimised model parameters can describe the stress-strain behaviour more accurately, as the optimisation process provides best fittings for all employed loading stages. The adoption of $t_{o}=1$ unit of time allows contribution of creep to be emphasised from the early stage of loading instead at the end of primary consolidation. $t_{o}=1$ unit of time is not influenced by the soil sample thickness, drainage conditions, and the choice of loading stage. $t_{o}$ is also the time value of the reference time-line, based on which the creep time is counted. Thus, with $t_{o}=1$ unit of time, the reference time-line encloses less viscous strain compared to $t_{o}=t_{E O P}$. Additionally, the corresponding creep strain limit and creep coefficient to $t_{o}$ $=1$ unit of time can describe the creep behaviour from $t=1$ unity. Two case studies including Hong Kong marine clay (Hong Kong) and Drammen clay (Norway) are presented to verify the developed method. The analyses of the results and discussions are included to examine and validate the developed method.

\section{Governing elastic viscoplastic equations}

Yin and Graham (1989) introduced an elastic viscoplastic model with the time-line concept. The time-line concept includes an instant time-line, a reference time-line, a limit time-line, and a series of equivalent time-lines. The linear logarithmic creep function results in an infinite creep strain as time approaches infinity. Therefore, Yin (1999) proposed a non-linear creep function including a creep strain limit and a creep coefficient as shown in Eq. (1). Fig. 1 shows the concept of the reference time-line and the limit time-line, as well as their relationship. The limit time-line is the line having equivalent time $t_{e}$ equal to infinity and creep rate equal to zero, and the creep strain limit can be defined by curve fitting creep strain data.

$$
\varepsilon_{z}^{v p}=\frac{\psi_{o}^{\prime}}{1+\frac{\psi_{o}^{\prime}}{\varepsilon_{l m}^{v p}} \ln \frac{t_{e}+t_{o}}{t_{o}}} \ln \frac{t_{e}+t_{o}}{t_{o}}
$$

where, $\varepsilon_{z}^{v p}$ is the vertical creep strain under a constant effective stress, $t_{e}$ is the equivalent time determined based on the reference time-line, $y_{o}^{\prime}$ is the initial stress-dependent creep coefficient at 


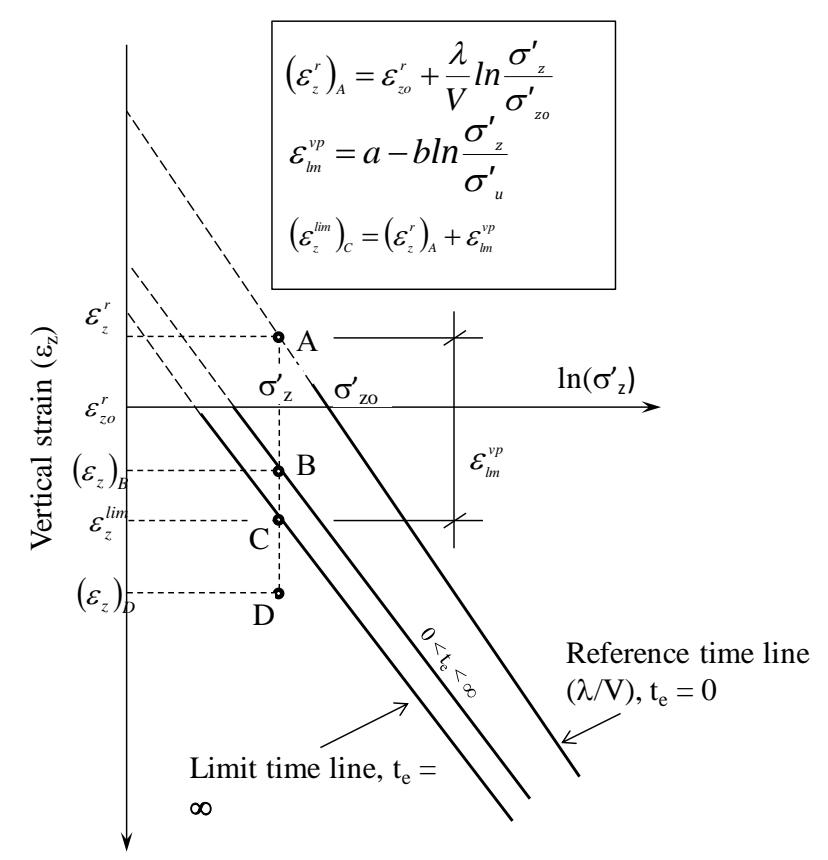

Fig. 1 Illustration of reference time-line and limit time-line

$t_{e}=0$, and $\varepsilon_{l m}^{v p}$ is defined as the stress-dependent creep strain limit, and $t_{o}$ is the time parameter and also time value of the reference time-line.

The incremental strain $d \varepsilon_{z}$ is the sum of the incremental elastic strain $d \varepsilon_{z}^{e}$ and the incremental visco-plastic strain $d \varepsilon_{z}^{v p}$. The incremental elastic strain $d \varepsilon_{z}^{e}$ is the differentiation of elastic strain $\varepsilon_{z}^{e}=\varepsilon_{z o}^{e}+\frac{\kappa}{V} \ln \left(\frac{\sigma_{z}^{\prime}}{\sigma_{u}^{\prime}}\right)$ (with $\varepsilon_{z o}^{e}$ being the elastic strain corresponding to the effective stress $\sigma_{u}^{\prime}=1$ $\mathrm{kPa}, \kappa / V$ is the elastic stiffness of the soil) with respective to $\sigma_{z}^{\prime}$, and $d \varepsilon_{z}^{v p}$ is the product of the visco-plastic strain rate $\dot{\varepsilon}_{z}^{v p}$ and the time increment $d t$.

$$
d \varepsilon_{z}=d \varepsilon_{z}^{e}+d \varepsilon_{z}^{v p}=\frac{\kappa}{V} \frac{1}{\sigma_{z}^{\prime}} d \sigma_{z}^{\prime}+\dot{\varepsilon}_{z}^{v p} d t
$$

The visco-plastic strain rate $\dot{\varepsilon}_{z}^{v p}$ results from the differentiation of Eq. (1) with time (Yin 1999).

$$
\dot{\varepsilon}_{z}^{v p}=\frac{\psi_{o}^{\prime}}{\left(t_{o}+t_{e}\right)} \frac{1}{\left(1+\frac{\psi_{o}^{\prime}}{\varepsilon_{l m}^{v p}} \ln \frac{t_{o}+t_{e}}{t_{o}}\right)^{2}}=\frac{\psi_{o}^{\prime}}{t_{o}}\left(1+\frac{\varepsilon_{z}^{r}-\varepsilon_{z}}{\varepsilon_{l m}^{v p}}\right)^{2} \exp \left(\frac{1}{\psi_{o}^{\prime}}\left(\frac{\varepsilon_{o}^{r}-\varepsilon_{z}}{1+\frac{\varepsilon_{z}^{r}-\varepsilon_{z}}{\varepsilon_{l m}^{v p}}}\right)\right)
$$

where, $t_{e}=t_{o} \exp \left(\frac{\psi_{o}^{\prime}}{\varepsilon_{l m}^{v p}}\left(\frac{\varepsilon_{z}^{r}-\varepsilon_{z}}{\varepsilon_{z}-\varepsilon_{z}^{r}-\varepsilon_{l m}^{v p}}\right)\right)-t_{o}, \quad \varepsilon_{z}^{r}=\varepsilon_{z o}^{r}+\frac{\lambda}{V} \ln \left(\frac{\sigma_{z}^{\prime}}{\sigma_{z o}^{\prime}}\right)$ is the reference strain under the 
applied stress $\sigma_{z}^{\prime}, \varepsilon_{z o}^{r}$ is the vertical strain corresponding to the vertical effective stress $\sigma_{z o}^{\prime}$, which is a model parameter.

Based on Eq. (2), depending on the location of stress-strain point, the strain rate is defined as follows (Yin 1999)

- For any $\left(\sigma_{z}^{\prime}, \varepsilon_{z}\right)$ point below the limit time-line (i.e., the soil is purely elastic.)

$$
\frac{\partial \varepsilon_{z}}{\partial t}=\frac{\kappa}{V \sigma \sigma_{z}}\left(\frac{\partial \sigma_{z}^{\prime}}{\partial t}\right)
$$

- For any $\left(\sigma_{z}^{\prime}, \varepsilon_{z}\right)$ point above the limit time-line

$$
\frac{\partial \varepsilon_{z}}{\partial t}=\frac{\kappa}{V \sigma \sigma_{z}}\left(\frac{\partial \sigma_{z}^{\prime}}{\partial t}\right)+\frac{\psi_{o}^{\prime}}{t_{o}}\left(1+\frac{\varepsilon_{z}^{r}-\varepsilon_{z}}{\varepsilon_{l m}^{v p}}\right)^{2} \exp \left(\frac{1}{\psi_{o}^{\prime}}\left(\frac{\varepsilon_{z}^{r}-\varepsilon_{z}}{1+\frac{\varepsilon_{z}^{r}-\varepsilon_{z}}{\varepsilon_{l m}^{v p}}}\right)\right)
$$

In order to obtain coupled governing equations for vertical strain and excess pore water pressure dissipation, the following assumptions are made:

- Soil is fully saturated,

- Soil particles and water are incompressible,

- The water flow and compression happen only in the vertical direction, and

The continuity equation $\left(\frac{\kappa}{\gamma_{w}} \frac{\partial^{2} u}{\partial z^{2}}=-\frac{\partial e_{z}}{\partial t}\right)$ should be satisfied

$$
\frac{k}{\gamma_{w}} \frac{\partial^{2} u}{\partial z^{2}}=-\frac{\partial e_{z}}{\partial t}=-\left(\frac{\kappa}{V \sigma \sigma_{z}}\left(\frac{\partial \sigma_{z}^{\prime}}{\partial t}\right)+\frac{\psi_{o}^{\prime}}{t_{o}}\left(1+\frac{\varepsilon_{z}^{r}-\varepsilon_{z}}{\varepsilon_{l m}^{v p}}\right)^{2} \exp \left(\frac{1}{\psi_{o}^{\prime}}\left(\frac{\varepsilon_{o}^{r}-\varepsilon_{z}}{1+\frac{\varepsilon_{z}^{r}-\varepsilon_{z}}{\varepsilon_{l m}^{v p}}}\right)\right)\right)
$$

where, $k$ is the coefficient of hydraulic conductivity, $\gamma_{w}$ is the unit weight of water, $u$ is the pore ater pressure equal to the sum of the excess pore water pressure $\left(u_{e}\right)$ and an initial equilibrium water pressure $\left(u_{o}\right), z$ is the vertical depth, $\varepsilon_{z}$ is the vertical strain and $t$ is the elapsed time.

If we assume $u_{o}$ remaining unchanged during the consolidation process, then $\frac{\partial^{2} u}{\partial z^{2}}=\frac{\partial^{2} u_{e}}{\partial z^{2}}$. In this paper, the external applied loading is assumed to be constant and independent of time. Thus, the total stress remains constant with time, but may vary with depth $z$. The coefficient of volume compressibility, $m_{v}=\frac{\partial \varepsilon_{z}}{\partial \sigma_{z}^{\prime}}=\frac{\kappa}{V \sigma_{z}^{\prime}}$, adopted in this study is not a constant parameter, but varies with depth and time due to the change of the effective stress $\sigma_{z}^{\prime}$. Thus, the stress-strain relation is not considered as linear. The stress increment in this study is applied instantly, and the initial excess pore water pressure is equal to the stress increment.

In Terzaghi's consolidation equation, the coefficient of volume compressibility, $m_{v}$, and the 
consolidation coefficient, are adopted as constant values. However, in this numerical solution, $m_{v}=\frac{\kappa}{V \sigma_{z}^{\prime}}$, adopted in Eq. (8a) is assumed to be changing with depth and time due to the change of $\sigma_{z}^{\prime}$. Similarly, $c_{v}=\frac{k}{\left(m_{v} \gamma_{w}\right)}$ changes with depth and time, since the coefficient of permeability $k$ and $m_{v}$ vary with depth and time. Moreover, the permeability of the soil $(k)$ also varies with depth and time employing Eq. (7). Eq. (7) is based on the relationship between the void ratio and the coefficient of permeability proposed by Taylor (1948) and the conversion between void ratio and vertical strain $\left(\left(\varepsilon_{z}=\left(e_{o}-e\right) /\left(1+e_{o}\right)\right)\right.$.

$$
\varepsilon_{z}=-\frac{c_{k}}{1+e_{o}} \log \frac{k}{k_{o}}
$$

where, $k_{o}$ is the initial permeability corresponding to the initial void ratio of $e_{o}$ (or at zero strain), $\varepsilon_{z}$ is the strain at a particular depth, and $c_{k}$ is the permeability change index.

Substituting $m_{v}$ and $c_{v}$ into Eqs. (4) and (5) yields to the coupled partial differential equations to evaluate the time dependent relationship between the vertical effective stress, excess pore water pressure and the vertical strain.

$$
\begin{gathered}
c_{v} \frac{\partial^{2} u}{\partial z^{2}}=\frac{\partial u}{\partial t}-\frac{1}{m_{v}} g\left(\varepsilon_{z}, \sigma_{z}^{\prime}\right) \\
\frac{\partial \varepsilon_{z}}{\partial t}=-m_{v}\left(\frac{\partial u}{\partial t}\right)+g\left(\varepsilon_{z}, \sigma_{z}^{\prime}\right)
\end{gathered}
$$

where,

- For any $\left(\sigma_{z}^{\prime}, \varepsilon_{z}\right)$ point below the limit time-line

$$
g\left(\varepsilon_{z}, \sigma_{z}^{\prime}\right)=0
$$

- For any $\left(\sigma_{z}^{\prime}, \varepsilon_{z}\right)$ point above the limit time-line

$$
g\left(\varepsilon_{z}, \sigma \sigma_{z}\right)=\frac{\psi_{o}^{\prime}}{t_{o}}\left(1+\frac{\varepsilon_{z}^{r}-\varepsilon_{z}}{\varepsilon_{l m}^{v p}}\right)^{2} \exp \left(\frac{1}{\psi_{o}^{\prime}}\left(\frac{\varepsilon_{z}^{r}-\varepsilon_{z}}{1+\frac{\varepsilon_{z}^{r}-\varepsilon_{z}}{\varepsilon_{l m}^{v p}}}\right)\right)
$$

The reference strain at the effective stress $\sigma_{z}^{\prime}$ (point A in Fig. 1) is defined using $\lambda / V$ and $\sigma_{z o}^{\prime}$. The limit strain at the effective stress $\sigma_{z}^{\prime}$ (point $\mathrm{C}$ in Fig. 1) is the sum of the reference strain $\varepsilon_{z}^{r}$ and the creep strain limit $\varepsilon_{l m}^{v p}$. As the stress - strain state at point B in Fig. 1 stays above the limit time-line, $g\left(\varepsilon_{z}, \sigma_{z}^{\prime}\right)_{B}$ is calculated by Eq. (8c). On the other hand, $g\left(\varepsilon_{z}, \sigma_{z}^{\prime}\right)_{D}=0$, since stress - strain state at point $D$ is below the limit time-line.

In summary, Eqs. (8a) and (8b) are the coupled partial differential equations to evaluate the time dependent stress - strain relationship of a soil layer under uniform vertical pressures. These equations are the combination of the elastic visco-plastic model with nonlinear creep function and 
the theory of consolidation. By solving these equations simultaneously, the time dependent strain (or the settlement of the soil layer) can be obtained. Besides, the variation of the excess pore water pressures can be evaluated not only with time, but also with depth. In order to solve these differential equations, a numerical solution using the Crank-Nicolson finite difference scheme is described in detail in Appendix A. Crank-Nicolson finite difference method is based on central difference approximation in space and the trapezoidal rule in time (Crank and Nicolson 1947). Crank-Nicolson method is fully implicit and unconditionally stable. Thus, the method can ensure the stability and convergence without requirement for the time step adjustment. Moreover, Crank-Nicolson method has minimal truncation errors compared with explicit and implicit finite difference methods (Chen et al. 2003, Grasselli and Pelinovsky 2008).

The finite difference solution for the numerical simulation which is implemented in the developed method requires generating the calculation grid with depth and time. Thus, the soil layer thickness is an input in the optimisation process. Additionally, the consolidation data during the excess pore water pressure can be utilised in the optimisation process to determine the model parameters. Therefore, the developed method can be applied to not only laboratory-scale soil sample, but also the thick soil layer in the field conditions where the dissipation process takes significant time to complete.

\section{Parameter determination applying trust-region reflective optimisation scheme}

The conventional procedure to determine the EVP model parameters can be considered simple for the instant timeline and reference timeline. However, the difficulty rises in the case of the non-linear creep function. After the excess pore water pressure becomes negligible, more data points are required to establish the relationship between the model creep parameters and the effective stress values. This means more loading stages (at least two) are required to define the function coefficients of $a, b, c$, and $d$ (Eqs. (A4a) and (A4b)). The adoption $t_{o}=t_{E O P}$ (the time at the end of primary consolidation) may lead to non-unique model parameters for the soil. Thus, in this study, a solution is proposed to obtain all of the EVP model parameters simultaneously by employing the trust-region reflective least squares algorithm in combination with the finite different solution explained in the above section.

\subsection{Least squares algorithm}

In recent years, in various application fields, the optimisation problems have become more complex and now involve a great number of variables and nonlinear equations. Thus, the large scale nonlinear least squares problems have been studied extensively (e.g., Gould et al. 2005, Yuan 2011). In this study, the proposed solution for determination of model parameters is based on nonlinear least squares fitting by incorporating an advanced optimisation procedure using the trust-region reflective algorithm.

For the purpose of least square optimisation, an objective function $f(t, x)$ is defined to calculate the average strain at each time point $t$ with parameters $x=\left[x_{1}, x_{2} \ldots x_{n}\right]$ and the measured data points $\left(t_{1}, y_{1}\right),\left(t_{2}, y_{2}\right), \ldots,\left(t_{m}, y_{m}\right)$. The optimisation will be a solution of the following problem.

$$
\min _{x} \sum_{i=1}^{m}\left(y_{i}-f\left(t_{i}, x\right)\right)^{2}
$$




\subsection{Trust-region reflective algorithm}

Since the least square optimisation has become more popular for research in many different fields, various algorithms have been proposed to solve the optimisation problems such as Newton method, Gauss-Newton method, and Lavenberg-Marquardt method (Geletu 2007). The trust-region optimisation method incorporated in the interior reflective Newton algorithm proposed by (Coleman and Li 1996) is a simple, yet powerful approach to solve bound constrained nonlinear minimisation problems. For a brief description of this approach, assume $f(x)$ is the function to be minimised with $x$ as a vector. The value of $x$ can be bounded by upper and lower constrains. The concept of the trust-region method is to approximate $f(x)$ with a quadratic function $q(s)$, which reflects the behaviour of function $f(x)$ in a neighbourhood $N$ around the current point $x$. That neighbourhood $N$ is called the trust-region. The trust-region subproblem of the method is to compute a trial step $s$ by minimising the area $N$. If $f(x+s)<f(x)$, the current point $x$ is updated to be $x+s$. This step is called successful, and the trust region can remain for the next step. Otherwise, the step is unsuccessful, and consequently $x$ remains unchanged, and the region $N$ will be reduced for the next step. Therefore, the challenging issue of the trust-region method is to solve its subproblem, computing the quadratic function $q(s)$ and to define the trust-region $N$. The general trust-region subproblem can be presented as Eg. (10).

$$
\begin{aligned}
& \min _{s} q(s)=\min _{s}\left(\frac{1}{2} s^{T} H s+s^{T} g\right) \\
& \text { such that }\|D s\| \leq \Delta
\end{aligned}
$$

where, $g$ is the gradient of $f(x)$ for the current $x, H$ is a symmetric matrix of second derivatives, $D$ is a diagonal scaling matrix, $\Delta$ is the trust-region radius $>0$ and $\|$.$\| is the second norm. Coleman$ and $\mathrm{Li}$ (1996) proposed the reflective Newton algorithm to minimise the quadratic function, i.e., to solve Eq. (10).

The approximation model $q(s)$ for the objective function does not have to be necessarily a quadratic function. A linear approximation model can be adopted, since the linear model can ensure the global convergence to first-order criteria information. However, the convergence rate would also be linear, which is consequently too slow. Meanwhile, a quadratic model is more effective, since a quadratic model can allow global convergence to the second-order and produce faster local convergence (Conn et al. 2009, Floudas and Pardalos 2008). Moreover, a quadratic model can capture the curvature of the non-linear function which cannot be achieved by a linear function (Conn et al. 2009, Murty 2010). Therefore, the quadratic function implemented in the optimisation scheme in this study, can handle more efficiently the non-linear equations of the EVP model to produce the best optimised results for the model parameters.

In particular, to solve Eq. (10) more quickly, $s$ can be restricted in a two dimensional subspace $S$. The subspace $S$ is spanned by two vector directions $s_{1}$ (the direction of the gradient $g$ ), and $s_{2}$ (the approximate Newton direction or a negative direction of curvature, $S_{2}^{T} H s_{2}<0$ ). Applying the trust-region method to a general nonlinear least squares problem.

$$
\min _{x} \sum_{i=1}^{n} f_{i}^{2}(x)=\min _{x} \sum\|F(x)\|_{2}^{2}
$$

where, $F(x)$ is the vector valued function having the $i$ th component equal to $f_{i}(x)$. 
To define the subspace $S$ for the problem more efficiently, an approximate Newton direction $s_{2}$ can be found by solving the following problem

$$
\min _{x}\|J s+F\|_{2}^{2}
$$

where, $J$ is the Jacobian of $F$. Eq. (12) can be approximately solved by applying the preconditioned conjugate gradient method to its normal equations in each iteration as follows

$$
J^{T} J S=-J^{T} F
$$

According to Strikwerda (2007), the preconditioned conjugate gradient method is an effective method to solve a large symmetric positive definite system of linear equations $A x-b=0$ with a large condition number. If matrix A has a large condition number $\kappa(A)$, where $\kappa(A)=\|A\|\left\|A^{-1}\right\|$ the slower the conjugate gradient method produces convergence. Thus, the concept of preconditioning is to reduce the condition number by transforming the original system $A x-b=0$ to $M^{-1}(A x-b)=0$, where $M$, known as a preconditioner for $A$, is a symmetric positive definite matrix.

After solving the problem given in Eq. (13), the vector directions of the subspace $S$ are determined, and consequently, the minimisation process can be accomplished. In summary, as presented by Geletu (2007) and Coleman and $\mathrm{Li}$ (1996), the trust-region reflective algorithm can briefly be described as follows:

- Step 1: $k=0$, choose an initial vector parameter $x_{0}$, trust-region size $\Delta_{k} \in(0, \bar{\Delta}), 0<\eta_{1}<$ $\eta_{2}<1,0<\gamma_{1}<1<\gamma_{2}$, tolerance $\varepsilon>0$

- Step 2: Compute the two dimensional subspace $S$ to find two subspace vectors $s_{1}$ and $s_{2}$

- Step 3: Solve Eq. (16) to find the trial step $s_{k}$

- Step 4: Compute $r_{k}=\frac{f\left(x_{k}\right)-f\left(x_{k}+s_{k}\right)}{q(0)-q\left(s_{k}\right)}$

$$
\text { If } r_{k} \geq \eta_{1} \text {, set } x_{k+1}=x_{k}+s_{k} \text {; otherwise, set } x_{k+1}=x_{k}
$$

- Step 5: Adjust the trust-region size $\Delta_{k+1}$

$$
\begin{gathered}
\text { If } r_{k} \geq \eta_{1}, \Delta_{k+1} \in\left(0, \gamma_{1} \Delta_{k}\right) \\
\text { If } \eta_{1} \leq r_{k}<\eta_{2}, \Delta_{k+1} \in\left(\gamma_{1} \Delta_{k}, \Delta_{k}\right) \\
\text { If } r_{k} \geq \eta_{2} \text { and }\left\|s_{k}\right\|=\Delta_{k}, \Delta_{k+1} \in\left(\Delta_{k}, \min \left(\gamma_{2} \Delta_{k}, \Delta_{k}\right)\right)
\end{gathered}
$$

- Step 6: If $\left\|g:=\nabla f\left(x_{k}\right)\right\| \leq \varepsilon$, the solution is convergence, and then the algorithm terminates ( $\varepsilon$ is the required tolerance). Otherwise, set $k=k+1$, and update $q\left(s_{k}\right)$ and the trust-region size $\Delta_{k}$, then repeat Steps 1 to 6 until a desired convergence is reached.

In regard to the trust-region reflective algorithms, the optimum values of the parameters can be ensured by several termination tolerances and the number of iterations in the optimisation process. The termination tolerances include the minimum changes in the values of the variables (i.e., the model parameters) and the minimum changes in the value of the objective function $f(x)$. Besides, 
the number of iterations can also be adjusted. In this study, the adopted tolerances for both variables and functions were $10^{-10}$ to ensure the accuracy of the optimised model parameters

\subsection{Parameters determination solution}

To apply the optimisation algorithm for the parameter determination in this study, the objective function $u(x)$ is the function to compute the absolute difference of the predicted $f\left(t_{i}, x\right)$ and measured $\left(y_{i}\right)$ values of vertical strain, in which $x$ is the vector of the required parameters.

$$
x=\left[x_{1}, x_{2}, x_{3}, x_{4}, x_{5}, x_{6}, x_{7}, x_{9}\right]=\left[a, b, c, d, \lambda / V, \sigma_{z o}^{\prime}, \kappa / V, k_{o}, c_{k}\right]
$$

and

$$
u(x)=\sum_{i=1}^{m}\left(y_{i}-f\left(t_{i}, x\right)\right)^{2}
$$

The user - defined function $f\left(t_{i}, x\right)$ is the coded function implemented in the finite difference solution described above to predict the average strain, and the excess pore water pressure of the soil with time using the set of parameters $x$. The measured data includes several sets of vertical strain - time curves for different applied stresses for a particular soil. In Eq. (15), $y_{i}$ is the average strain at a time point $t_{i}$ while $i$ can change from 1 to $m$. Here $m$ is the total number of available data points of all stress increments.

The required initial information of each stress increment (i.e., each loading stage) includes soil properties (initial void ratio $e_{o}$, initial thickness $H_{0}$ ) and the loading conditions (initial vertical total stress $\sigma_{z}$, stress increment $\Delta \sigma$, and initial strain $\varepsilon_{z i}$ ). Incorporating the initial trial set of parameters and initial conditions into the finite difference solution as described in Fig. 3 yields the predicted sets of average vertical strain and time for each stress increment.

Assume there are $l$ number of loading stages where $l$ is a positive integer. Each of loading stages has $n_{k}$ number of data points (e.g., Stage $l$ has $n_{l}$ data points available). Thus, the total number of data points $(m)$ can be calculated using Eq. (16).

$$
m=\sum_{k=1}^{l} n_{k}
$$

where, $n_{k}$ are the data point numbers corresponding to loading stage $k$, where $k$ changes from 1 to $l$

For an individual loading stage (i.e., loading stage $k$ ), the squares of the differences between the predicted and measured data are calculated as shown in Eq. (17)

$$
u(x)=\sum_{j=1}^{n_{k}}\left(y_{j}-f\left(t_{j}, x\right)\right)^{2} \text { for } k=1 \text { to } l
$$

Thus, Eq. (17) can be restated as Eq. (18) 


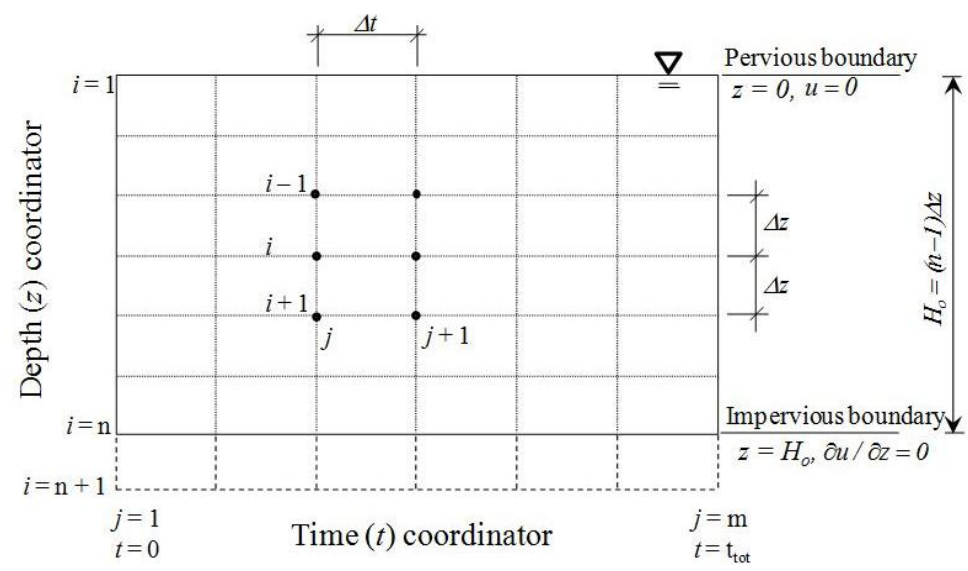

(a)

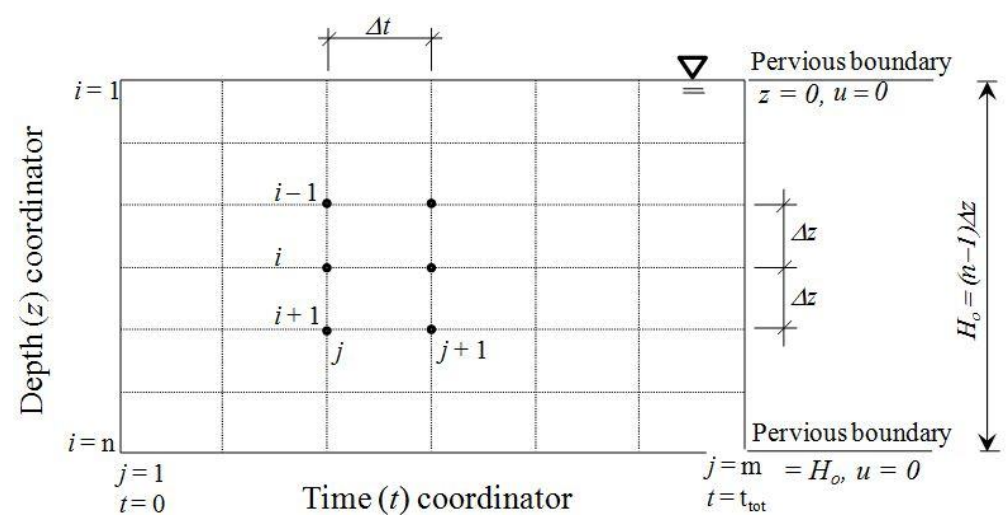

(b)

Fig. 2 General layout of finite difference calculation grids and boundary conditions: (a) one-way drainage; and (b) two-way drainage

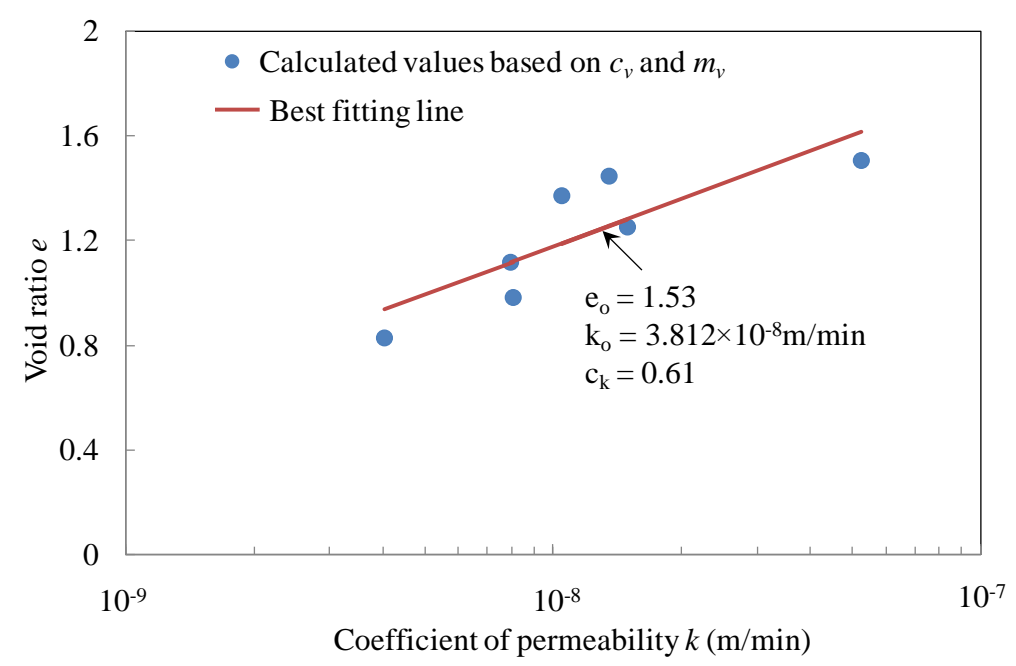

Fig. 3 Void ratio and coefficient of permeability relationship 


$$
u(x)=\sum_{k=1}^{l} \sum_{j=1}^{n_{k}}\left(y_{j}-f\left(t_{j}, x\right)\right)^{2}
$$

Applying the trust-region reflective least squares algorithm, the optimal set of parameters can be determined by solving the following optimisation problem (Eq. (19))

$$
\min _{z} u(x)=\min _{z} \sum_{k=1}^{l} \sum_{j=1}^{n_{k}}\left(y_{j}-f\left(t_{j}, x\right)\right)^{2}
$$

In this study, the above mentioned algorithms, representing the trust-region reflective least squares, is implemented and coded in MATLAB using "lsqnonlin" function. In cooperation with the finite difference solution for the EVP model, the optimisation procedure can be used efficiently to obtain the required parameters all together.

For the standard soil sample thickness (i.e., $H_{o}=20 \mathrm{~mm}$ ), the standard consolidation test duration (i.e., 24 hours) with load increments covering the future construction load can be employed to obtain the EVP model parameters. For the thicker soil sample, the minimum test duration should be enough for the average required effective stress level (depending on future construction load) to be achieved. Since creep compression occurs during the excess pore water pressure dissipation, the optimisation procedure allows utilisation of consolidation data during dissipation to determine the visco-plastic parameters. It should be noted that the longer duration of loading stages can be utilised to improve the accuracy of the optimisation process, as more data points would be available for optimisation.

The proposed approach is to strengthen the merits of the EVP model with the non-linear creep function by obtaining a set of unique material parameters with $t_{o}$ adopted as a unit of time. However, the optimisation method can be applied for other constitutive models in which the creep parameter cannot be determined during the dissipation of the excess pore water pressure (e.g., the soft soil creep model in Vermeer and Neher (1999), the EVP model of Nash (2001). The time parameter corresponding to the reference time-line used to define the creep parameter is usually adopted as $t_{E O P}$ for the laboratory sample or 1 day (Nash 2001, Vermeer and Neher 1999). In order to apply the least squared method to optimise the model parameters, the measurements and the corresponding predictions must be ready to employ. The predictions can be obtained by different numerical methods such as finite difference and finite element schemes. The similar procedure of optimisation can be incorporated in the numerical solutions, and it is not necessary to assume the time parameter or the reference time line as 24 hours or the time at the end of primary consolidation. Moreover, the number of the required model parameters should be less than the number of available measured data. Thus, the model parameters can be obtained by implementing any possible numerical solution for the predictions into the trust-region reflective least square algorithm.

In order to evaluate the accuracy of the parameter determination method as well as the finite difference solution for the EVP model with a nonlinear creep function, two case studies are simulated and interpreted in the following sections.

\section{Case study 1 - Hong Kong Marine Clay}

A set of consolidation data results of Hong Kong marine clay reported in Yin (1999) is adopted 
in this case study to evaluate the ability of the proposed TRRLS method. The studied soil (a mixture of clay, silt and fine sand) was sieved and reconstituted to obtain consistent test specimens. As reported in Yin (1999), the specific gravity of the soil $\left(G_{s}\right)$ was 2.66 , and the initial water content $\left(w_{o}\right)$ was $57.4 \%$. Thus, the initial void ratio $e_{o}=w_{o} G_{s}$ was calculated to be 1.53 , assuming that the soil sample was fully saturated. The soil specimen was subjected to multiple stage loading tests using Casagrande type oedometer setup. The applied stress started from $10 \mathrm{kPa}$, then increased to $400 \mathrm{kPa}$ by the stress increment ratio $\left(\Delta \sigma_{z} / \sigma_{z i}^{\prime}\right)$ of 1 . Later, the soil was unloaded back to $50 \mathrm{kPa}$ and reloaded to $800 \mathrm{kPa}$ with the same stress increment ratio. The duration of each loading stage was about 1 day, except for $200 \mathrm{kPa}$ and $800 \mathrm{kPa}$ stages with durations of 33 and 18 days, respectively.

Adopting the trust-region reflective least squares (TRRLS) algorithm for the parameter determination described in detail in the previous sections, four stages of effective stresses $100 \mathrm{kPa}$, $200 \mathrm{kPa}, 400 \mathrm{kPa}$ and $800 \mathrm{kPa}$ were employed to determine all model parameters (Fig. 3). Similar to Yin (1999), aforementioned four loading stages are all in normally consolidated range to be used for creep model parameter determination. In this study, the above four loading stages are used to determine not only the creep model parameters, but also the elastic $(\kappa / V)$ and elastic - plastic $\left(\lambda / V\right.$ and $\left.\sigma_{z o}^{\prime}\right)$ parameters.

The adopted initial data of the four stages including the initial thickness, the initial vertical strain, the initial and final total stresses, and the initial excess pore water pressure, obtained from the laboratory measurements (Fig. 3) are summarised in Table 1. Considering the oedometer testing procedure, it can be assumed that the effect of external applied stress is immediate; thus, the initial total stress $\left(\sigma_{z}\right)_{(i, 1)}$ at $t=0$ is taken as the total final stress $\sigma_{z f}$. The two-way drainage condition is applied in this simulation.

The initial coefficient of permeability $\left(k_{o}\right)$ and the permeability change index $\left(c_{k}\right)$ are estimated based on the values of $c_{v}$ and $m_{v}$ calculated using the oedometer compression results $\left(k=c_{v} m_{v} \gamma_{w}\right)$. As a result shown in Fig. $3, k_{o}=3.812 \times 10^{-8} \mathrm{~m} / \mathrm{min}$ and $c_{k}=0.61$ with $e_{o}=1.53$, which are adopted in the numerical simulation of Yin (1999)'s approach and the TRRLS approach. It should be noted that $k_{o}$ and $c_{k}$ can be measured directly using constant or falling head permeability tests for clay soil samples consolidated under different effective stresses. The permeability of a soil is a physical material property influenced by characteristics of the soil including soil fabric, composition, porosity, pore sizes and the property of the permeant (Lambe and Whitman 1969, Raj 2008). Therefore, the values of $c_{k}$ and $k_{o}$ obtained from consolidation test results based on $m_{v}$ and $c_{v}$ and from the constant or falling head permeability tests should be similar, if the samples of the two tests have the soil condition such as void ratio, the applied hydraulic gradient as well as the soil structure (not disturbed).

Based on the initial information and soil properties, the model parameters obtained by the

Table 1 Initial information adopted in the optimisation procedure to determine the model parameters for Hong Kong marine clay

\begin{tabular}{cccccc}
\hline \hline Loading stage & $H_{o}(\mathrm{~m})$ & $\varepsilon_{z i}(\%)$ & $\sigma_{z i}(\mathrm{kPa})$ & $\sigma_{z f}=\sigma_{z i}+\sigma_{z}(\mathrm{kPa})$ & $u_{e i}=\Delta \sigma_{z}(\mathrm{kPa})$ \\
\hline $100 \mathrm{kPa}$ & 0.02 & 8.50 & 50 & 100 & 50 \\
$200 \mathrm{kPa}$ & 0.02 & 13.75 & 100 & 200 & 100 \\
$400 \mathrm{kPa}$ & 0.02 & 19.60 & 200 & 400 & 200 \\
$800 \mathrm{kPa}$ & 0.02 & 25.25 & 400 & 800 & 400 \\
\hline
\end{tabular}


Table 2 Summary of the adopted model parameters for Hong Kong marine clay

\begin{tabular}{|c|c|c|c|c|}
\hline \multicolumn{3}{|c|}{ Model parameters } & TRRLS method & Yin (1999) approach \\
\hline Instant time-line & \multicolumn{2}{|c|}{$\kappa / V$} & 0.0062 & 0.0116 \\
\hline \multirow{2}{*}{ Reference time-line } & \multicolumn{2}{|c|}{$\lambda / V$} & 0.0901 & 0.0833 \\
\hline & \multicolumn{2}{|c|}{$\sigma_{z o}^{\prime}(\mathrm{kPa})$} & 62.8 & 24.8 \\
\hline \multirow{5}{*}{ Equivalent time-line } & \multicolumn{2}{|c|}{$t_{o}(\min )$} & 1 & 49 \\
\hline & \multirow{2}{*}{$\varepsilon_{l m}^{v p}$} & $a$ & 0.1539 & 0.0617 \\
\hline & & $b$ & 0.0108 & 0.0064 \\
\hline & \multirow{2}{*}{$\psi_{\mathrm{o}}^{\prime}$} & $c$ & 0.1 & 0.0139 \\
\hline & & $d$ & 0.0060 & 0.0014 \\
\hline \multirow{3}{*}{$\begin{array}{l}\text { Soil permeability } \\
\text { parameters }\end{array}$} & \multirow{2}{*}{\multicolumn{2}{|c|}{$\begin{array}{c}e_{o} \\
k_{o}(\mathrm{~m} / \mathrm{min})\end{array}$}} & \multirow{2}{*}{\multicolumn{2}{|c|}{$\begin{array}{c}1.53 \\
3.91 \times 10^{-7}\end{array}$}} \\
\hline & & & & \\
\hline & \multicolumn{2}{|c|}{$c_{k}$} & \multicolumn{2}{|c|}{0.836} \\
\hline
\end{tabular}

proposed TRRLS method are presented in Table 2 along with the model parameters obtained by Yin's (1999) procedure. As shown in Table 2, the optimised parameters for the non-linear creep function are higher than the parameters obtained by Yin's (1999) procedure. This is reasonable since the parameters have been optimised using the data during the dissipation of the excess pore water pressures. The creep compression during the consolidation contributes to the value of the creep strain limit and the creep coefficients.

In order to evaluate the developed finite difference solutions incorporating the proposed parameter determination procedure, the time dependent vertical strains of four stress stages are predicted for both sets of parameters (i.e., the proposed TRRLS method and Yin's (1999) procedure) and compared to laboratory measurements in Fig. 4. The laboratory test results are used for validation. The model parameters then were used to analyse the influence of the soil sample thickness on the stress-strain behaviour of soils by providing the predictions for five different soil layer thicknesses (from $0.02 \mathrm{~m}$ to $5.12 \mathrm{~m}$ ). Fig. (4) shows the reported coefficients of determination $\left(R^{2}\right)$ are higher than 0.9 for both sets of parameters, thus both parameter determination methods are efficient to match the laboratory results.

Since the proposed method can utilise all the consolidation data during the excess pore water pressure, the TRRLS approach adopts more data points to predict the viscous (creep) parameters including $a, b, c, d$ coefficients compared to Yin's (1999) procedure. The predictions of the settlements are in good agreement with the measurements not only after the end of primary consolidation but also during the dissipation of excess pore water pressure with the coefficient of determination $R^{2}$ greater than 0.97 as shown in Fig. 4. Since the optimisation procedure includes several loading stages simultaneously, the model parameters provide the best fitting curves for all loading stages involved. Although the predictions by the TRRLS approach in Fig. 4 do not always over predict the final vertical strains as the predictions obtained by Yin's (1999) procedure, the disparity between the predictions and the measurements are not significant with high coefficient of determinations $R^{2}$.

In the next step, the optimised model parameters using the TRRLS approach are used to predict the average strain and the excess pore water pressure for thicker soil deposits. The predictions presented in Figs. 5 to 8 are not to compare the efficiency of the methods since the actual field 


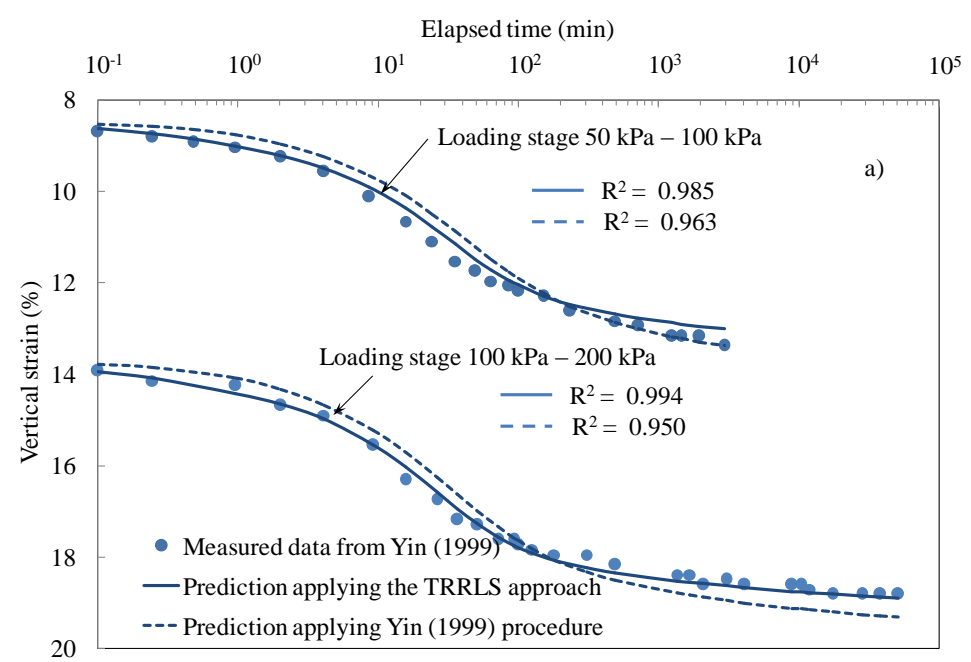

(a)

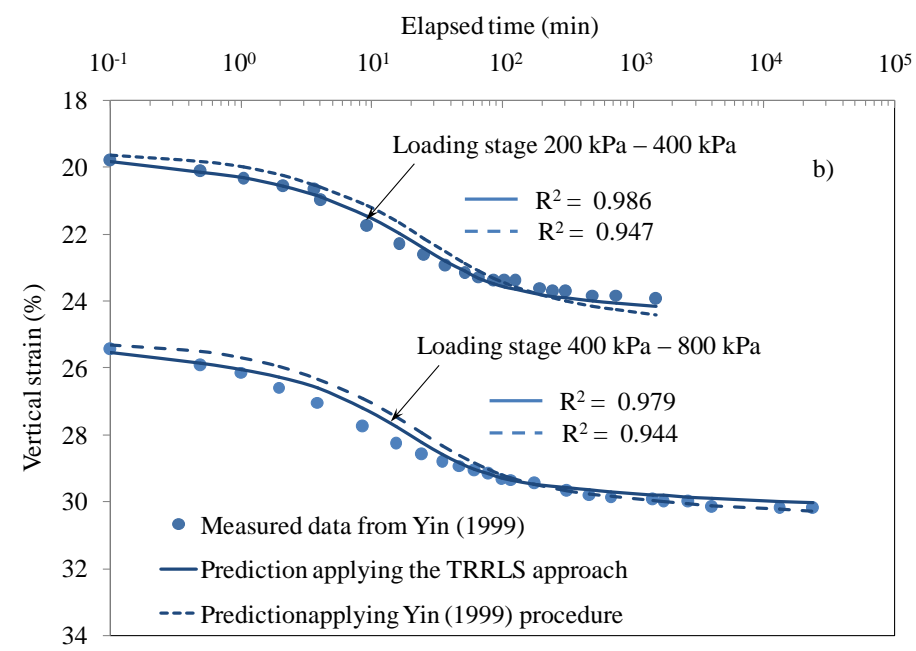

(b)

Fig. 4 Predicted time dependent vertical strain under (a) $100 \mathrm{kPa}$ and $200 \mathrm{kPa}$; (b) $400 \mathrm{kPa}$ and $800 \mathrm{kPa}$ vertical stresses using the parameters by the conventional method of Yin (1999) and the optimised parameters using TRRLS approach

measurements are not available. However, the predictions are provided to show the influence of the model parameters on the predictions for the thicker soil samples as well as the influence of the soil sample thickness on the stress-strain-time behaviour. Additionally, the predictions adopting Yin (1999) approach are presented to assess the trends of the predictions adopting the optimised model parameters. The prediction results show that there are similar variation patterns of predictions obtained by both methods. In this study, the influence of the soil layer thicknesses on the time depended settlement and the variation of the excess pore water pressure can be observed and discussed. Figs. 5(a) and 5(b) illustrate the time dependent stress-strain relationship known as Hypothesis B. 


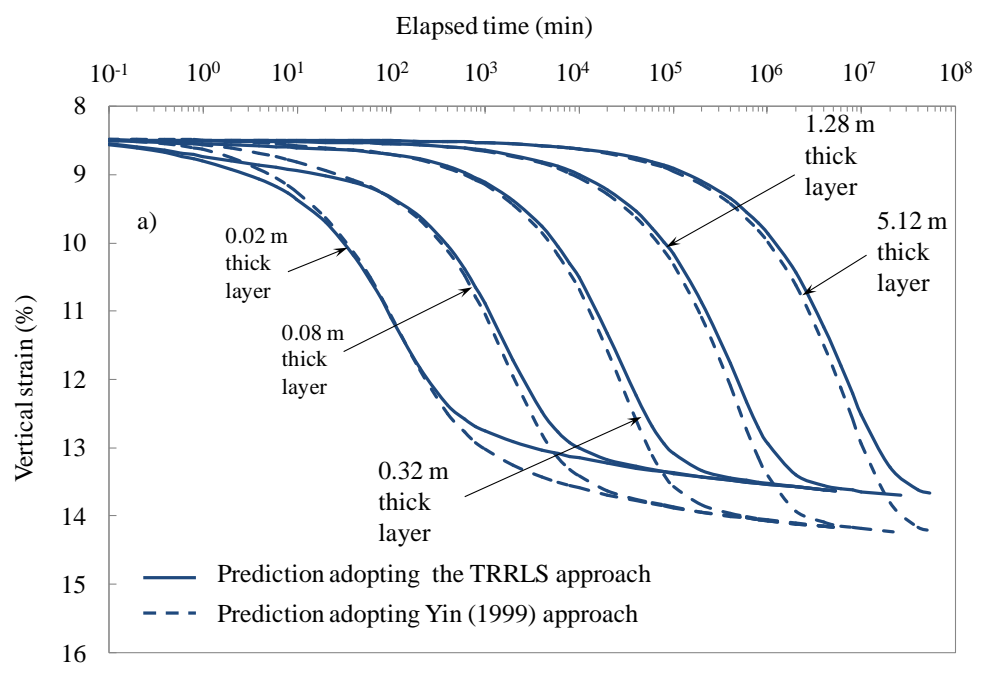

(a)

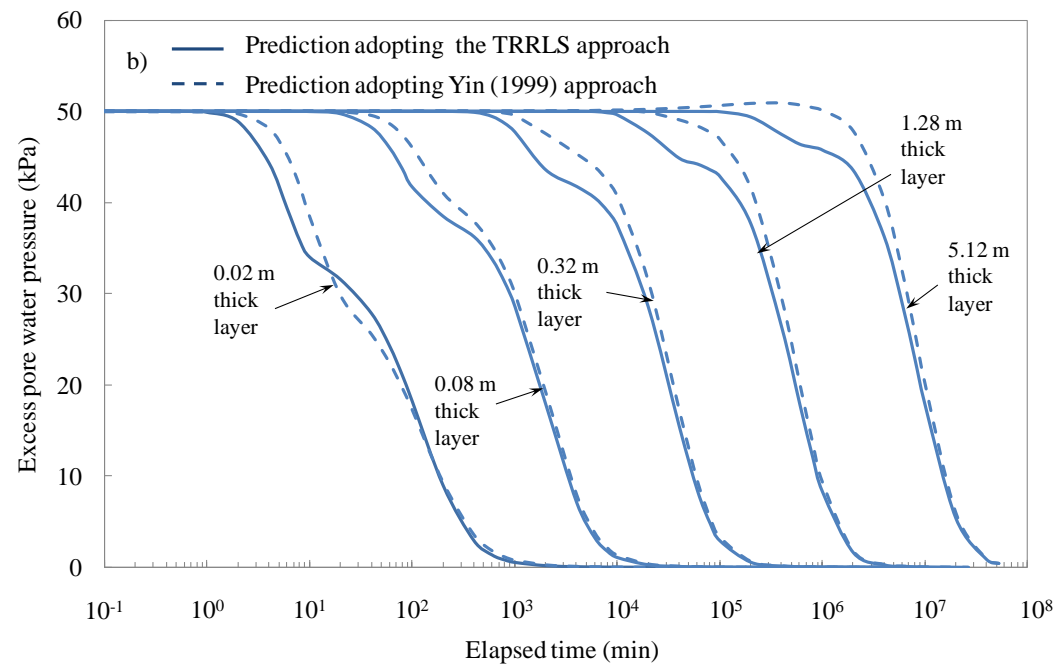

(b)

Fig. 5 Predictions of (a) average strain of various thickness soil layers; and (b) excess pore water pressure at the base of soil layers adopting model parameters obtained from TRRLS approach and Yin (1999) approach

The five different thicknesses $\left(H_{o}\right)$ adopted are $0.02 \mathrm{~m}, 0.08 \mathrm{~m}, 0.32 \mathrm{~m}, 1.28 \mathrm{~m}$ and $5.12 \mathrm{~m}$. The external applied stress increment is $50 \mathrm{kPa}$ to increase the vertical effective stress from $50 \mathrm{kPa}$ to $100 \mathrm{kPa}$. In this analysis, the soil layers are assumed uniform, and the clay layers of different thicknesses start with the same initial vertical strain and stress conditions. The soil deposits are assumed to be free drained at the top surface and impervious at the bottom. The duration of loading time is 10 years for the specimens of the first four thicknesses, while the loading times for $1.28 \mathrm{~m}$ and $5.12 \mathrm{~m}$ thick soil deposit are 50 and 100 years, respectively, in order to observe the reverse $S$ shaped curve of the average strain with logarithm of time. Fig. 5(a) shows the prediction 
of the average strain with time, while Fig. 5(b) indicates the time variation of the excess pore water pressure at the impervious boundary of the soil layers.

Fig. 6 shows the influence of the soil thickness on the average vertical strain, when 90\%, 95\% and $98 \%$ of the excess pore water pressures at the base of the soil specimens are dissipated. In the semi-logarithmic scale of Fig. 6, the curves of the average strain at different degrees of dissipation are almost parallel, and the average strain at a particular degree of dissipation increases with the increase of the soil thicknesses. For example, according to Fig. 6, the prediction applying TRRLS model parameters shows that at $90 \%$ dissipation the average strain increases by $3.8 \%, 6.3 \%, 8.1 \%$ and $9.5 \%$ for $0.08 \mathrm{~m}, 0.32 \mathrm{~m}, 1.28 \mathrm{~m}$ and $5.12 \mathrm{~m}$ thick samples in comparison to $0.02 \mathrm{~m}$ thick sample, respectively. A similar trend of variation of the average strain with the increase of soil layer thickness is observed at $95 \%$ and $98 \%$ dissipation and also by the predictions adopting parameters obtained from Yin (1999)'s approach. It is also noted that the difference between the average strains is more significant as the soil specimen thickness increases from $0.02 \mathrm{~m}$ to $0.08 \mathrm{~m}$. As can be seen in Fig. 6, adopting the model parameters obtained from TRRLS approach, the differences of the average strain at $90 \%, 95 \%$, and $98 \%$ dissipation between $0.02 \mathrm{~m}$ and $0.08 \mathrm{~m}$ are $5.8 \%, 4.9 \%$ and $4 \%$, respectively.

Compression induced by creep is accumulated as the thickness increases, and the vertical strain curves of thicker soil layers will merge to the vertical strain curve of the thin specimen after a period of loading time. As observed in Fig. 5(a), the strain curves of five specimens are almost parallel during the dissipation process of the excess pore water pressure, while the strain curves shift to the right as the sample thickness increases. However, the average strain curves of thicker specimens (i.e., $0.08 \mathrm{~m}, 0.32 \mathrm{~m}, 1.28 \mathrm{~m}$ to $5.12 \mathrm{~m}$ ) tends to merge to the settlement curve of the thinnest specimen (i.e., $0.02 \mathrm{~m}$ ), only when the excess pore water pressure at the impervious base of the layer approaches zero.

Meanwhile, Fig. 5(b) shows that the excess pore water pressure at the impervious base is influenced by the soil layer thickness. As the thickness of the soil layer increases, the curves of the excess pore water pressure at the base are shifted to the right with similar patterns. The dissipation

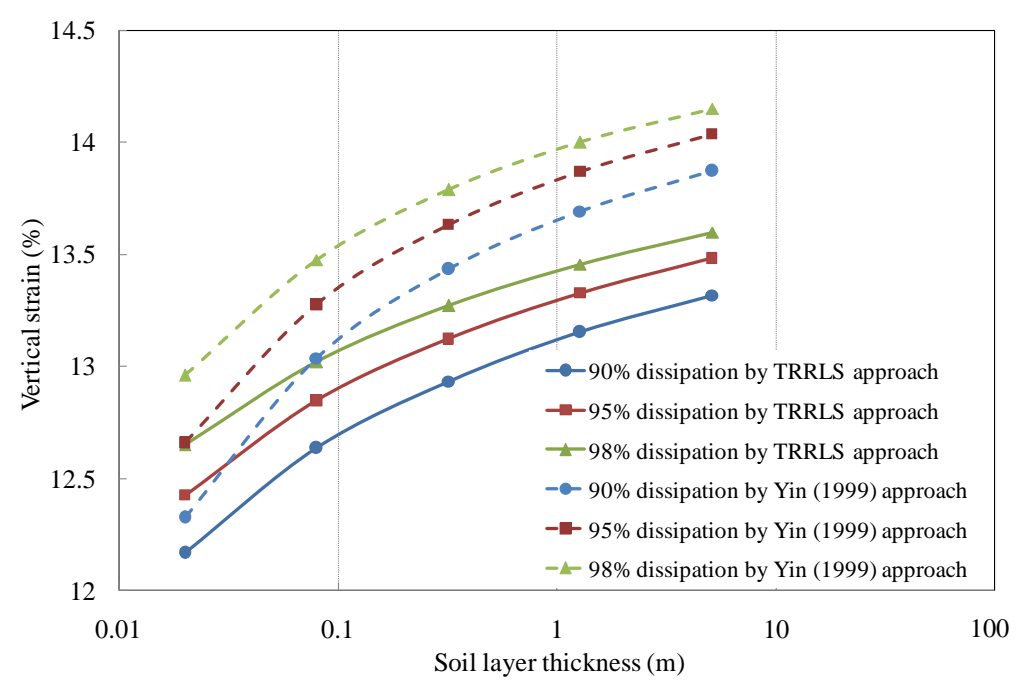

Fig. 6 Influence of soil thickness on the average vertical strain at 90\%, 95\% and 98\% dissipation of excess pore water pressure at the impervious boundary 


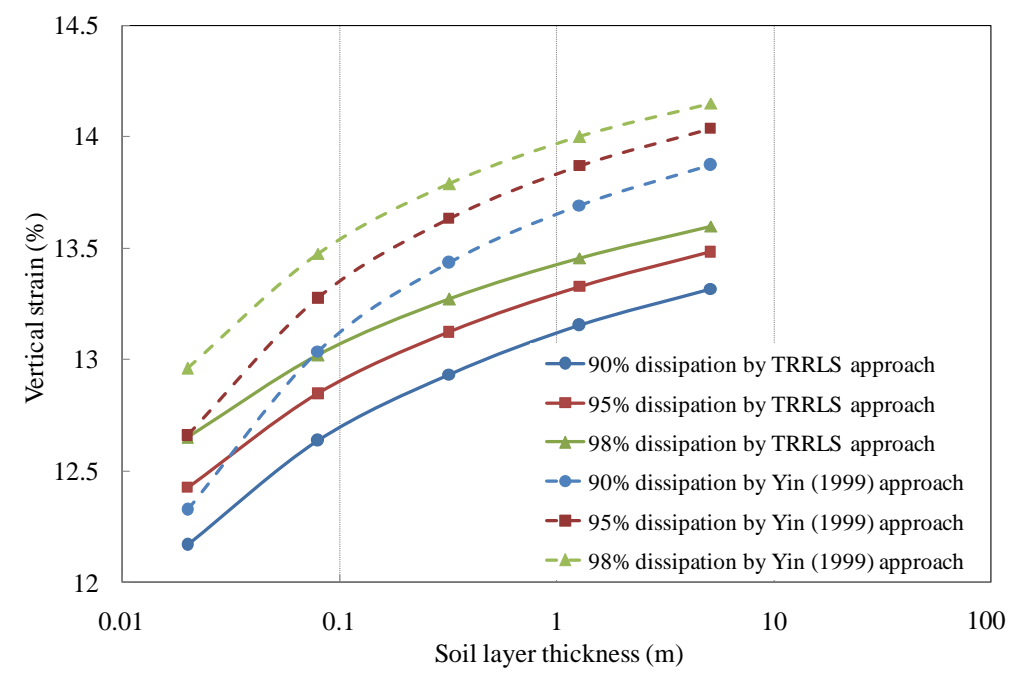

Fig. 6 Influence of soil thickness on the average vertical strain at 90\%, 95\% and 98\% dissipation of excess pore water pressure at the impervious boundary

of the excess pore water pressure varies with different rates during the consolidation process before approaching zero. Referring to Fig. 5(b), it can be seen that the excess pore water pressure dissipation at the impervious base layer delays before proceeding with various rates until approaching an almost constant value. It is noted that the amount of delayed time increases with increasing soil deposit thickness. As the drainage path for water flowing toward the drainage boundary is expected to increase with an increase in the deposit thickness, the required time for water travelling through the drainage path also increases. The delayed time observed in Fig. 4(b) for the soil specimens of $0.02 \mathrm{~m}, 0.08 \mathrm{~m}, 0.32 \mathrm{~m}, 1.28 \mathrm{~m}$ and $5.12 \mathrm{~m}$ are approximately $1 \mathrm{~min}, 20$ $\mathrm{min}, 200 \mathrm{~min}, 8,000 \mathrm{~min}$, and 10,000 min, respectively. During the delayed time, the settlement presented by the average strain also tends to be delayed as observed in Fig. 5(a). Corresponding to the excess pore water pressure dissipation pattern, the average vertical strain also increases significantly. When the dissipation process is almost completed, the compression continues mainly due to viscous behaviour of soil under an almost constant effective stress with a creep strain rate, reducing with time.

Figs. 7(a)-(b) depict the variations of the average creep strain limit $\left(\varepsilon_{l m}^{v p}\right)$ the average creep coefficient $\left(\psi_{o}^{\prime}\right)$, and the average creep parameter $(\psi)$ with time. Figs. 7(a)-(b) indicate that both $\varepsilon_{l m}^{v p}$ and $\psi_{o}^{\prime}$ are not constant, and change during the excess pore water pressure dissipation process. As soon as the dissipation completes, these model parameters reach the constant values, since the effective stress remains constant after increasing to the maximum value. So while the creep coefficient $\left(\psi_{o}^{\prime}\right)$ remains constant, when the vertical effective stress is constant; the creep parameter $(\psi / V)$ will decrease with time based on Eq. (26) and as illustrated in Fig. 8(a). The creep parameter $(\psi / V)$ is comparable with the secondary compression coefficient $C_{a \varepsilon}$.

The patterns of these two parameters (i.e., $\varepsilon_{l m}^{v p}$ and $\psi_{o}^{\prime}$ ) with time are similar to the variation pattern of excess pore water pressure in Fig. 5(b), as $\varepsilon_{l m}^{v p}$ and $\psi_{o}^{\prime}$ are directly related to the effective stress and consequently to the excess pore water pressure. The average creep strain limit as well as the average creep coefficient decrease with the increase of the effective stress. In other words, during the dissipation of the excess pore water pressure, the effective stress keeps 


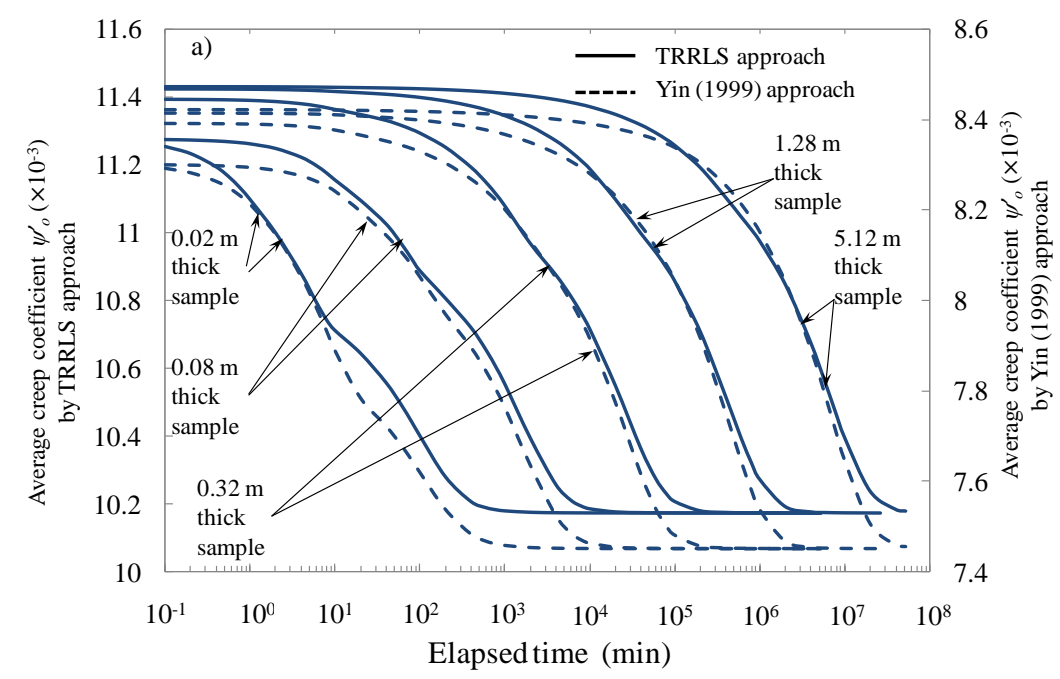

(a)

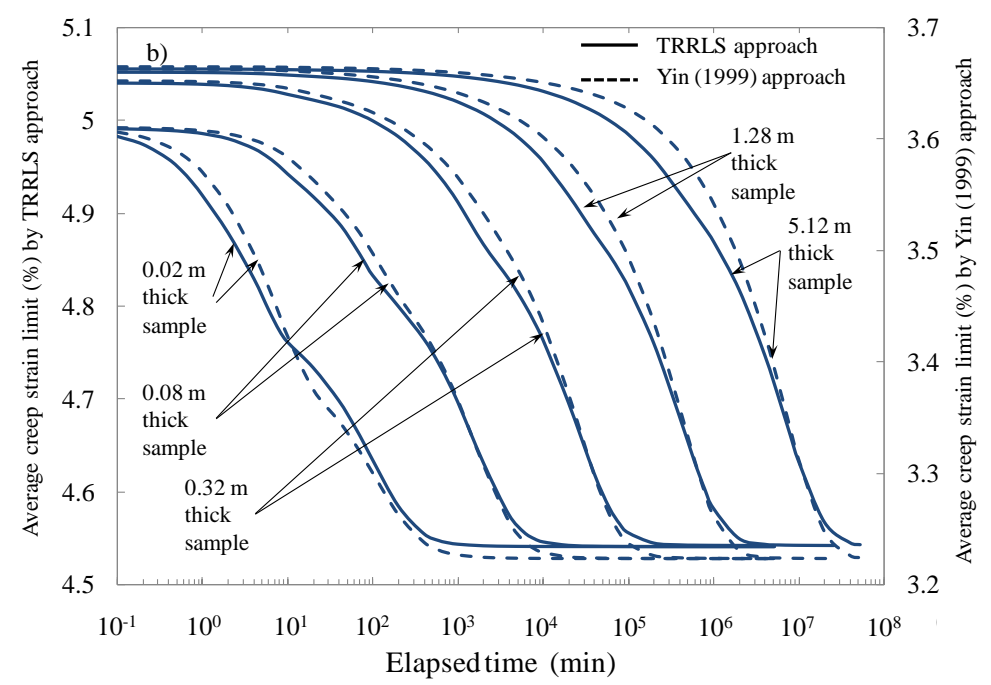

(b)

Fig. 7 Variation of (a) the average creep coefficient $\psi_{o}^{\prime}$; and (b) the average creep strain limit $\varepsilon_{l m}^{v p}$

increasing, resulting in decreasing $\varepsilon_{l m}^{v p}$ and $\psi_{o}^{\prime}$.

Although both $\varepsilon_{l m}^{v p}$ and $\psi_{o}^{\prime}$ decrease with the increase of the effective stress, the bell shaped pattern of the creep parameter $(\psi / V)$ (Fig. 8(a)) shows that the creep parameter $(\psi / V)$ is not only effective stress dependent, but also time dependent. As the dissipation of the excess pore water pressure accelerates after the delayed time, the creep parameter $(\psi / V)$ significantly increases. Once reaching the maximum value, the creep parameter $(\psi / V)$ decreases gradually with time.

Fig. 8(b) shows the variation of the average creep strain rates, $\dot{\varepsilon}_{z}^{v p}$, with time. When the effective stress increases during the dissipation of the excess pore water pressure, the creep strain rate also increases with time. In the semi logarithmic space of effective stress-vertical strain, as the effective stress increases in the early stages of the dissipation process, the stress-strain state point 
keeps moving to the right. Based on the time-line concept, each equivalent time-line has a unique creep strain rate, and the higher equivalent time $t_{e}$ is associated to the smaller creep strain rate (Yin and Graham 1994). Consequently, as the effective stress increases, the equivalent time-line associated to that effective stress moves away from the limit time-line, resulting in the increase in the creep strain rate and the decrease in the equivalent time $t_{e}$. When the dissipation of excess pore water pressure is almost completed, and the maximum effective stress of the stress increment is almost established, the creep strain rate gradually decreases. After the effective stress reaches the maximum value, and the compression is allowed to continue under the constant effective stress, the equivalent time $t_{e}$ increases and the equivalent time-line moves toward the limit time-line. As a result, the associated creep strain rate decreases.

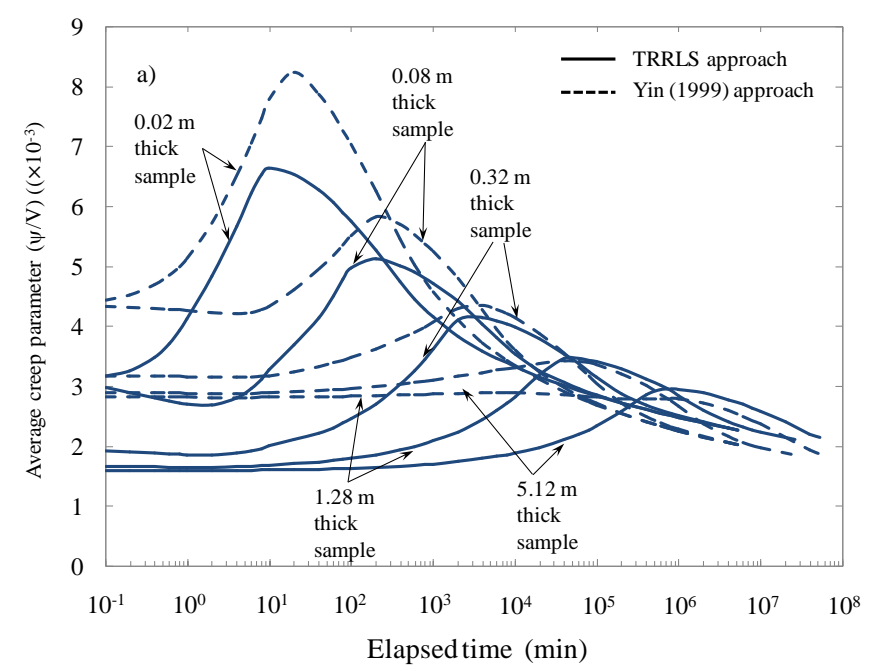

(a)

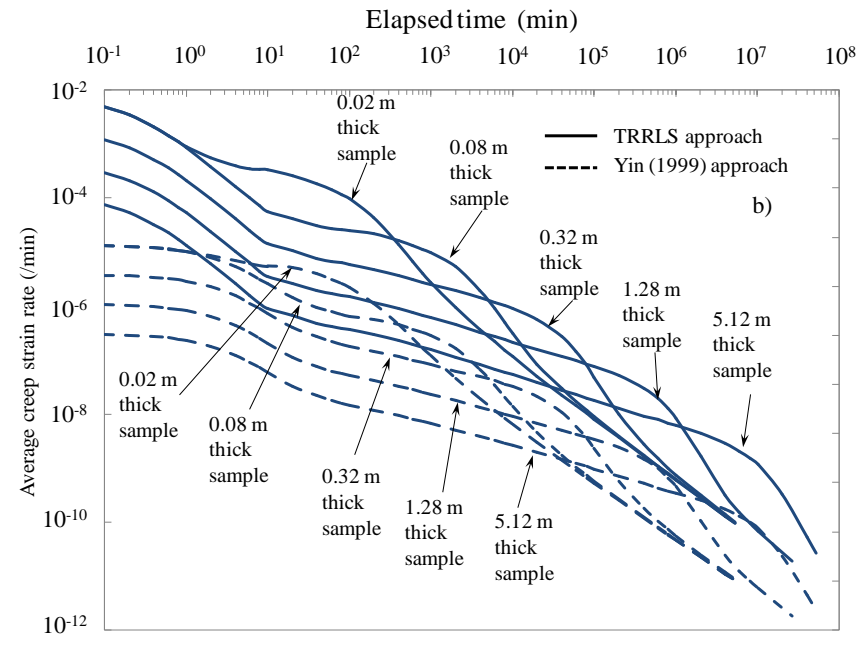

(b)

Fig. 8 Variation of (a) the average creep parameter $\psi / V$, and (b) the average creep strain rate $\dot{\varepsilon}_{v p}$ with time 
Figs. 8(a)-(b) also show the influence of the soil deposit thickness on the variation of the creep parameter $(\psi / V)$ and the average creep strain rate $\left(\dot{\varepsilon}_{z}^{v p}\right)$. The thicker soil layer has lower creep parameters, and consequently a slower creep strain rate. Although the thicker soil layer has a lower creep strain rate, the required time to achieve insignificant excess pore water pressure (known as the end of primary consolidation) is much higher than the corresponding required time for the thinner soil layer as previously shown in Fig. 5(b). As a result, the compression of the thicker soil layer at the end of the conventional primary consolidation (i.e., when the effective stress reaches an almost constant value) is greater than the compression of the thinner soil layer. Hence, the variation of $\psi / V$ during the dissipation process is notable and the simplifying assumption of a constant creep coefficient during the dissipation process as adopted in the previous studies (e.g., Gnanendran et al. 2006, Vermeer and Neher 1999) are realistic.

In brief, adopting the Crank-Nicolson finite difference solution and the model parameters obtained from TRRLS approach fitting the laboratory consolidation data can be used to predict reasonable patterns of the time dependent compression as well as the dissipation of the excess pore water pressure in soft soil deposits. Additionally, in Case study 1, the compression (strain) of the soil deposit for a given excess pore water pressure dissipation level increases with the increase of the soil thickness. As expected, the dissipation of the excess pore water pressure is delayed, as the thickness of the soil layer increases. In order to further evaluate the proposed approach adopting TRRLS to obtain EVP model parameters, Case study 2 on Drammen Clay is presented to predict the time dependent behaviour of the soft soil samples with different thicknesses.

\section{Case study 2 - Drammen Clay (Berre and Iversen 1972)}

Berre and Iversen (1972) carried out a series of consolidation tests on Drammen Clay specimens with four different thicknesses using modified oedometer apparatus recording the variation of the excess pore water pressure at the base with time. Drammen Clay (Norwegian soft clay) was slightly overconsolidated, marine post-glacial clay obtained from depths of $5.2 \mathrm{~m}$ to 6.7 $\mathrm{m}$ in Drammen, Norway. The heights of soil specimens were $0.0188 \mathrm{~m}, 0.0757 \mathrm{~m}, 0.15 \mathrm{~m}$, and $0.45 \mathrm{~m}$. The thickest specimen $(0.45 \mathrm{~m})$ was comprised of three $0.15 \mathrm{~m}$ high sub-specimens connected in series with free drainage at the top of the topmost specimen, and no drainage at the base of the lowest specimen. The pore water pressure was measured at the base of each specimen. Multiple stage loading tests with five stress increments were applied to all specimens. The duration of the first three stages was 1 day, while the last two increments (Increments 4 and 5) had longer duration ( 5 days for each increment). Berre and Iversent (1972) presented the measurements of the vertical strain and the excess pore water pressure at the base of each specimen at two stress increments (Increments 4 and 5) as shown in Figs. 10-13.

In this paper, the test results from the last two increments (Increments 4 and 5) (see Table 3) for $0.0188 \mathrm{~m}$ thick specimen are used to determine the model parameters. Adopting the optimised model parameters, the average strains and the excess pore water pressures at the base of the thicker soil specimens are predicted to compare with the experimental measurements. The details of initial input information for the predictions are presented in Table 3 . The initial void ratio $e_{o}$ of each soil specimen is derived from the initial water content $w_{o}$ assuming that soil specimens are fully saturated. According to Andersen et al. (1980), the specific gravity of Drammen Clay is 2.76. The initial strains summarised in Table 3 were obtained from the laboratory observations reported by Berre and Iversen (1972). The model parameters obtained by applying TRRLS approach are 
Table 3 Initial information of four specimens of Drammen Clay (data from Berre and Iversen 1972)

\begin{tabular}{|c|c|c|c|c|c|c|c|c|}
\hline Test & Increment & & $H_{o}(\mathrm{~m})$ & $\begin{array}{l}\varepsilon_{z i} \\
(\%)\end{array}$ & $\begin{array}{c}\sigma_{z i} \\
(\mathrm{kPa})\end{array}$ & $\begin{array}{c}\sigma_{z f}=\sigma_{z i}+\Delta \sigma_{z} \\
(\mathrm{kPa})\end{array}$ & $\begin{array}{c}u_{e i}=\Delta \sigma_{z} \\
(\mathrm{kPa})\end{array}$ & $e_{o}=2.76 \mathrm{w}$ \\
\hline \multirow{2}{*}{ A } & 4 & & 0.0188 & 2.33 & 55.3 & 92.5 & 37.2 & \multirow{2}{*}{1.58} \\
\hline & 5 & & 0.0188 & 6.01 & 92.5 & 140.2 & 47.7 & \\
\hline \multirow{2}{*}{ B } & 4 & & 0.0757 & 1.19 & 55.9 & 93.3 & 37.4 & \multirow{2}{*}{1.59} \\
\hline & 5 & & 0.0575 & 5.54 & 93.3 & 140.5 & 47.7 & \\
\hline \multirow{2}{*}{$\mathrm{C}$} & 4 & & 0.150 & 1.09 & 55.2 & 92.5 & 37.3 & \multirow{2}{*}{1.59} \\
\hline & 5 & & 0.150 & 4.46 & 92.5 & 140.2 & 47.7 & \\
\hline \multirow{6}{*}{$\mathrm{D}$} & & & $H_{o} / 3$ & 1.26 & & & & \multirow{6}{*}{1.62} \\
\hline & 4 & 0.450 & $2 / 3 H_{o}$ & 1.47 & 53.4 & 89.2 & 35.8 & \\
\hline & & & $H_{o}$ & 1.08 & & & & \\
\hline & \multirow{3}{*}{5} & \multirow{3}{*}{0.450} & $H_{o} / 3$ & 6.30 & & & & \\
\hline & & & $2 / 3 H_{o}$ & 4.73 & 89.2 & 134.7 & 45.5 & \\
\hline & & & $H_{o}$ & 5.17 & & & & \\
\hline
\end{tabular}

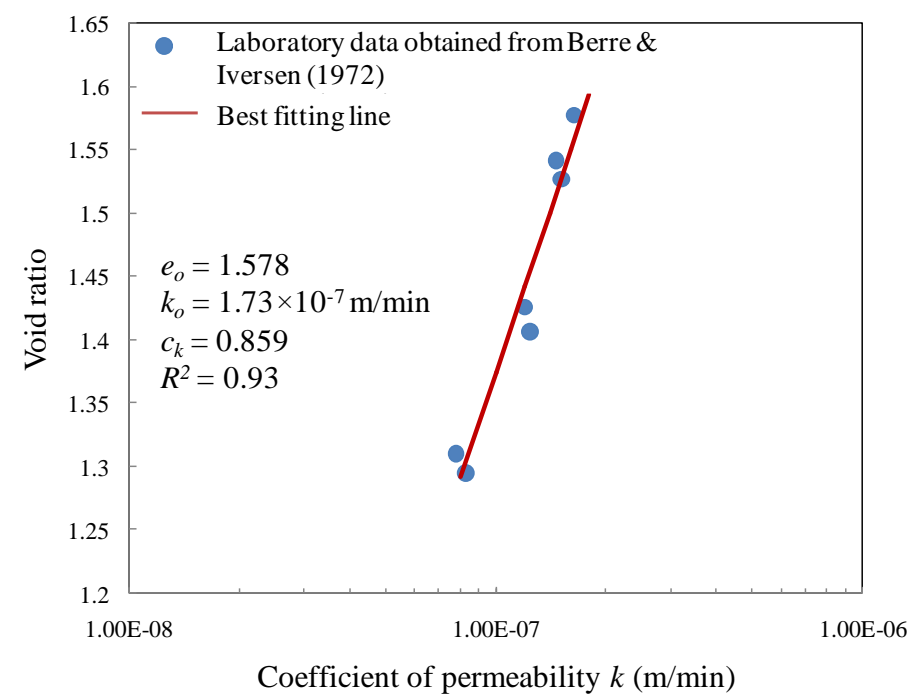

Fig. 9 Void ratio - permeability relationship for Drammen clay

presented in Table 4 along with the model parameters of the EVP model with linear creep function reported in Yin and Graham (1996).

It should be noted that the conventional approach proposed by Yin (1999) could not readily used to predict the non-linear creep strain rate and limit functions in this study adopting only two stress increments. Applying Yin's (1999) procedure to Increment 4 with $t_{o}=40$ min (which was reported in Yin and Graham 1996), the creep strain limit of this increment appeared as a negative number. Thus, the relationship between the effective stress and the creep strain limit cannot be established by applying Yin's (1999) procedure. In order to apply Yin's (1999) procedure for this soil, more loading stages are required. Yin and Graham (1996) applied their original EVP model 
with linear creep function, and the predictions obtained by the model parameters of the original EVP model reported in Yin and Graham (1996) were used to compare with the predictions by the TRRLS approach. Fig. 9 shows the relationship between the void ratio and permeability based on the measured values of permeability and water content reported in Berre and Iversen (1972). As a result, the permeability change index $c_{k}$ obtained as the slope of a straight line in the space of $e$ $\log _{10}(k)$ is 0.859 , while the initial permeability is $k_{o}=1.73 \times 10^{-7} \mathrm{~m} / \mathrm{min}$.

Figs. 10-13 present the predictions of average vertical strain and the excess pore water pressure at the base of the four specimens by the TRRLS approach and the linear EVP model. For the

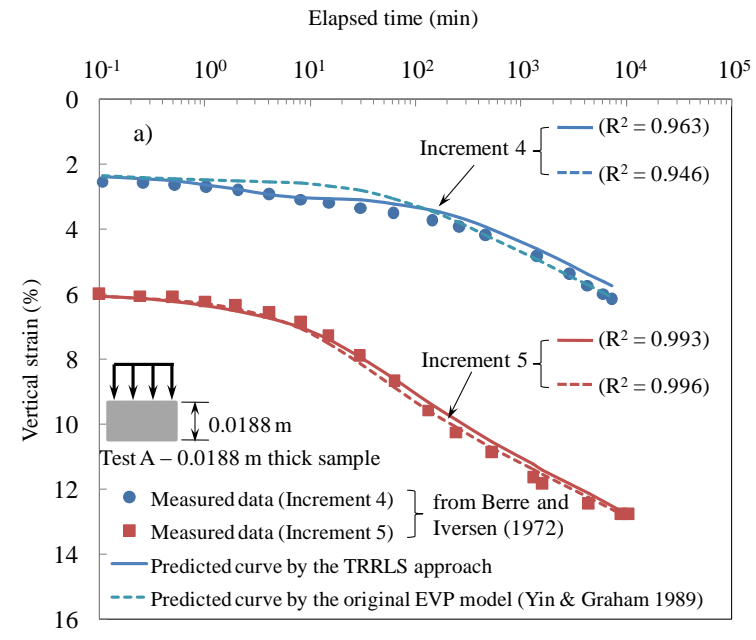

(a)

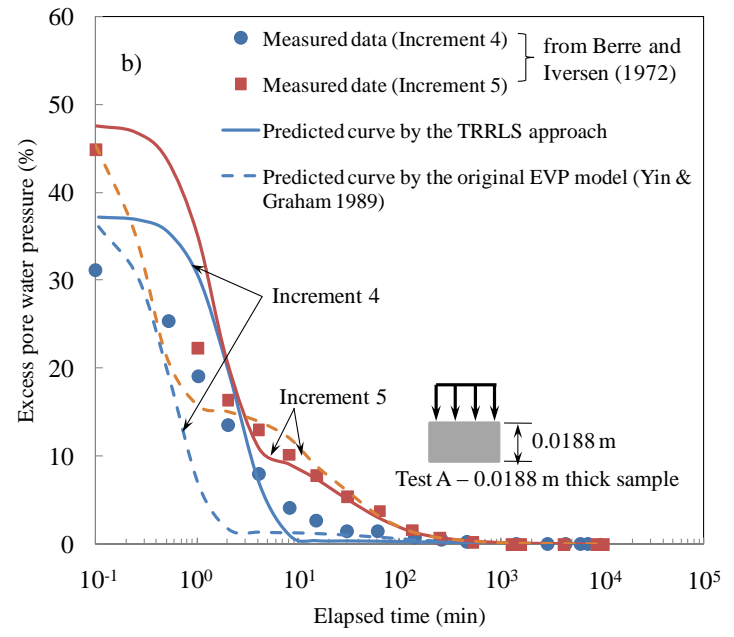

(b)

Fig. 10 Comparison of the prediction and the measured data for Test A $(0.0188 \mathrm{~m})$ : (a) the average vertical strain; and (b) the excess pore water pressure at the base for Drammen Clay

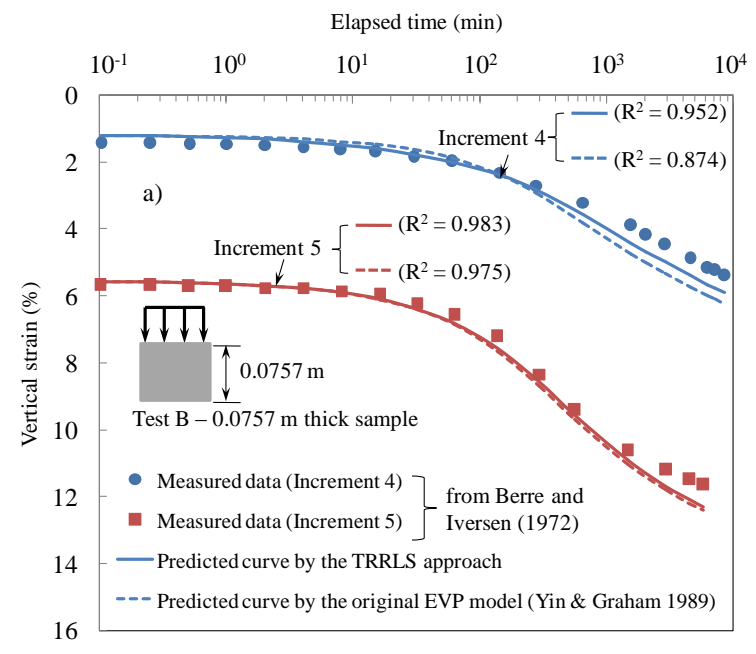

(a)

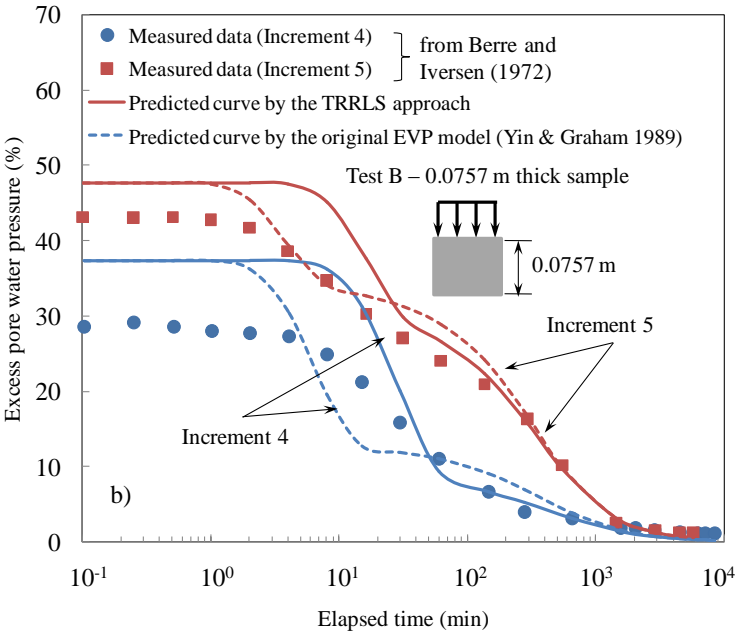

(b)

Fig. 11 Comparison of the prediction and the measured data for Test B $(0.075 \mathrm{~m})$ : (a) the average vertical strain; and (b) the excess pore water pressure at the base for Drammen Clay 


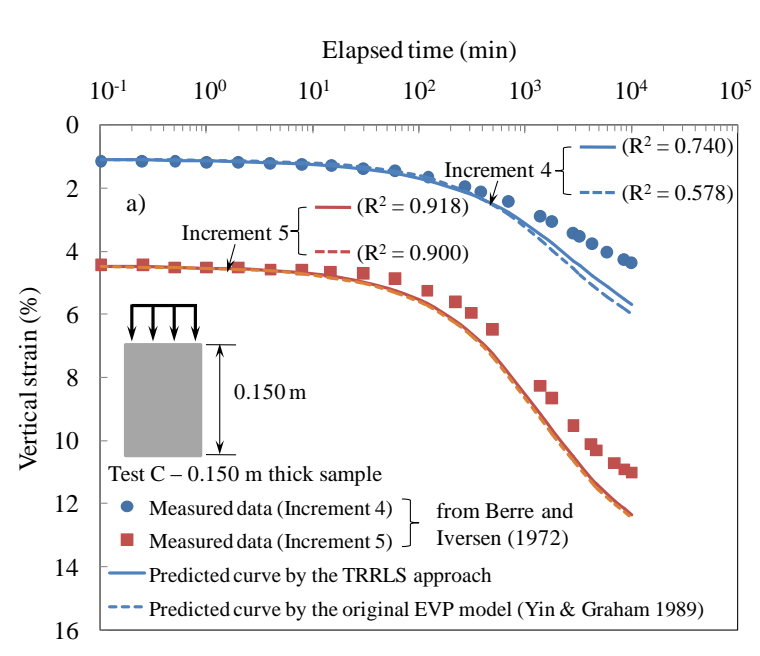

(a)

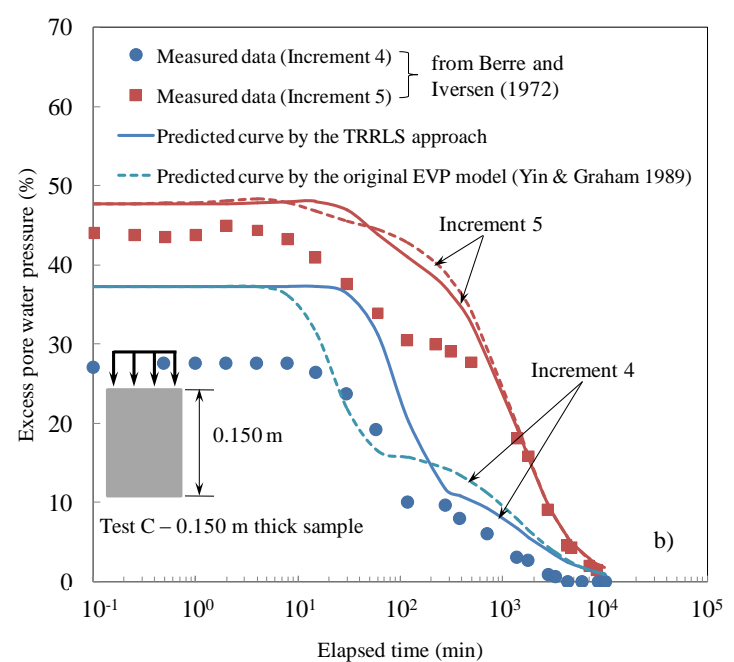

(b)

Fig. 12 Comparison of the prediction and the measured data for Test $\mathrm{C}(0.150 \mathrm{~m})$ : (a) the average vertical strain; and (b) the excess pore water pressure at the base for Drammen Clay

thickest specimen $(0.45 \mathrm{~m})$, the excess pore water pressures at three locations are presented. As reported in Berre and Iversen (1972), the stress-strain state of the soil specimens shifts from overconsolidated to normally consolidated range, when the effective stress increases from $\sigma_{z 3}^{\prime}=$ $55.3 \mathrm{kPa}$ to $\sigma_{z 4}^{\prime}=92.5 \mathrm{kPa}$. Thus, TRRLS approach can employ effectively the consolidation data to determine the model parameters.

As observed in Figs. 10-13, the numerical predictions of excess pore water pressures and the average vertical strains are in good agreement with the laboratory measurements. The predictions obtained by the TRRLS approach expose some improvement compared to the predictions obtained by the linear EVP model. Moreover, the influence of the non-linear creep function on the long-term behaviour cannot be clearly observed, since the observation time is not sufficient. The model parameters determined by TRRLS is able to predict the average strain of four tests with high coefficient of determination $\left(R^{2}\right)$ in comparison to laboratory measurements as shown in Figs. 10 to 13 . The prediction of Increment 4 of test C (Fig. 12(a)) has the lowest $R^{2}$ value in comparison to the results of other tests. According to Berre and Iversen (1972), the effect of side friction of the sample of Test $\mathrm{C}$ was notable and reported about 5.4-10.1\% for Increment 4 and $8.9-5.1 \%$ for Increment 5 measured at the beginning and at the end of the increment respectively. The side friction was considered relatively small, and was not measured for all of the tests. Thus, the measured results were not corrected for side friction (Berre and Iversen 1972). Although the side friction was suggested not remarkable, it is possible that Test $\mathrm{C}$ predictions are influenced as a result of highest side friction.

The variation patterns of the excess pore water pressure are clearly influenced by the thickness of the soil specimen. Based on Fig. 10 for the thinnest specimen $(0.0188 \mathrm{~m})$, the dissipation of the excess pore water pressure at the base occurs very rapidly in both increments (less than 10 minutes). As observed in Figs. 11(b), 12(b), and 13(b)-(c), for the thicker soil specimens, the dissipation process is inclined to delay some times before hastily accelerating, and the time delay increases with the thickness. In this case study, the increase of the excess pore water pressure 
during the dissipation is obviously observed in the prediction of the thickest sample (Test D) during Increment 5 (shown in Fig. 13(c)). The measurements of the excess pore water pressures at the base of Test D sample in Increments 4 and 5 show the increase of the excess pore water pressure during the dissipation process, particularly during the delayed period and before the dissipation accelerates (Figs. 13(b)-(c)). The prediction for Test D also shows the increase in excess pore pressures during the dissipation in Increment 5.

The contribution of viscous effect can be the reason for the increase of the excess pore water pressure (Yin and Graham 1996, Yin and Zhu 1999). As the soil sample thickness is high enough

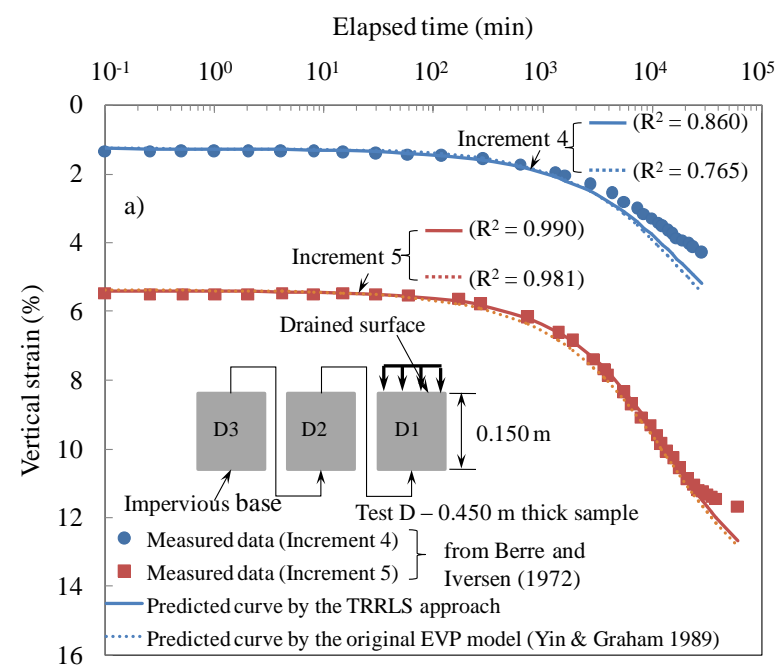

(a)

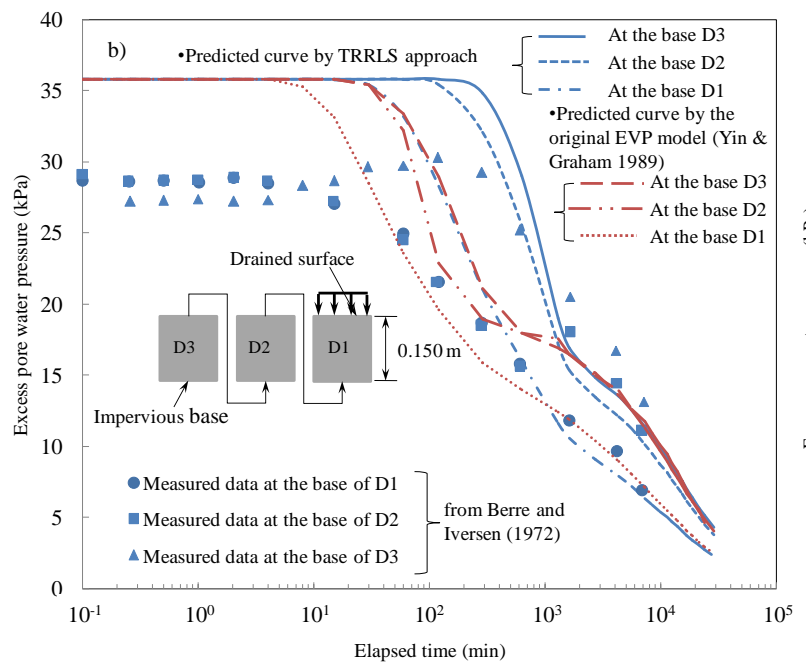

(b)

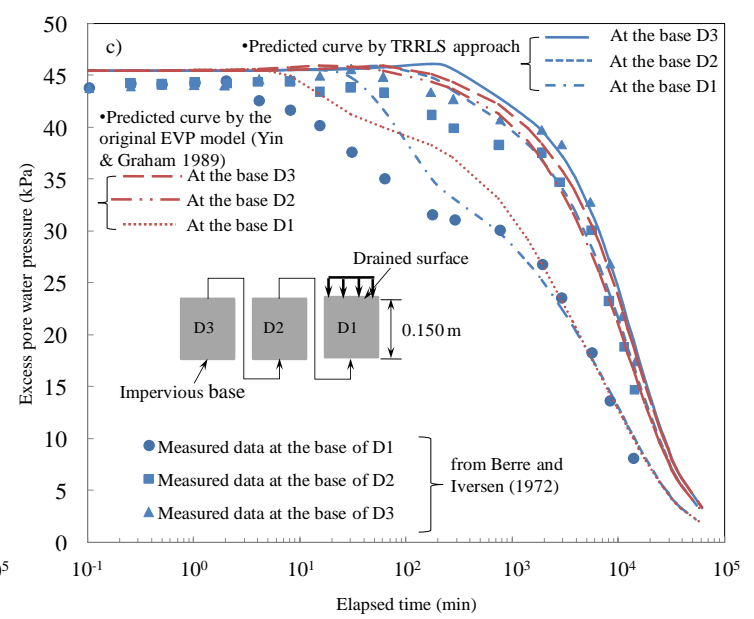

(c)

Fig. 13 Comparison of the prediction and the measured data for Test D $(0.450 \mathrm{~m})$ : (a) the average vertical strain (\%), (b) the excess pore water pressures of Increment 4, and (c) the excess pore water pressures of Increment 5 for Drammen Clay 
to cause the delay in the dissipation of the excess pore water pressure, creep compression occurs locally due to the constant effective stresses at local soil elements. The creep compression reduces the drainage path of the pore water, resulting in void water near the impervious base locally blocked to flow out. At those locations where pore water is blocked, vertical strains remain almost unchanged, leading to relaxation effect. During relaxation, the strain keeps constant, and the effective stress decreases. Thus, the excess pore water pressure increases. However, the increase of the excess pore water pressure is suggested to occur when the effective stress sufficiently exceeds the initial preconsolidation pressure (Yin and Graham 1996).

It is noted that the initial measured values of excess pore water pressures reported in Berre and Iversen (1972) were lower than the applied stress increment for saturated soil, causing the

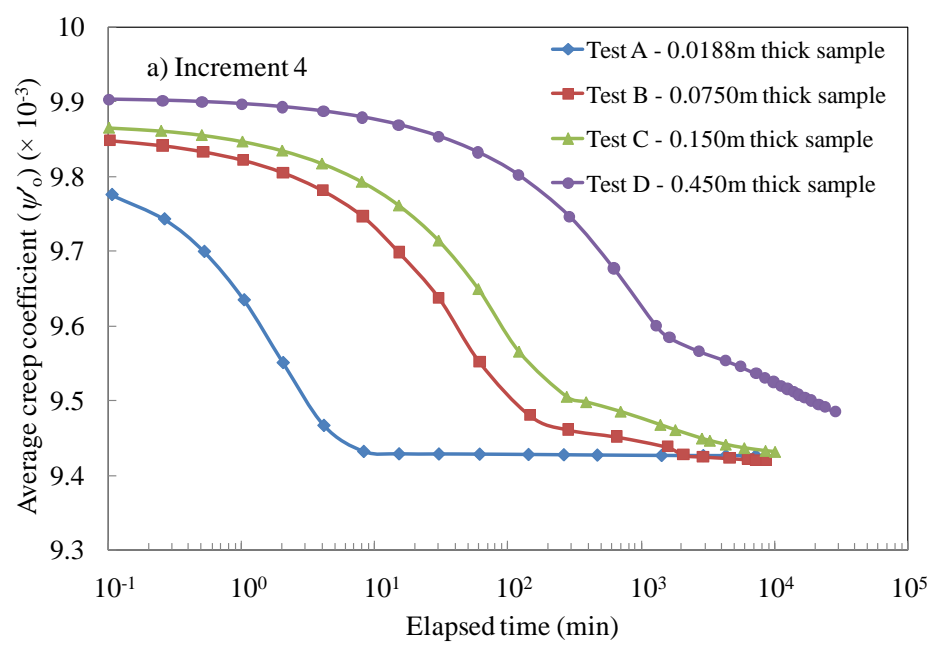

(a)

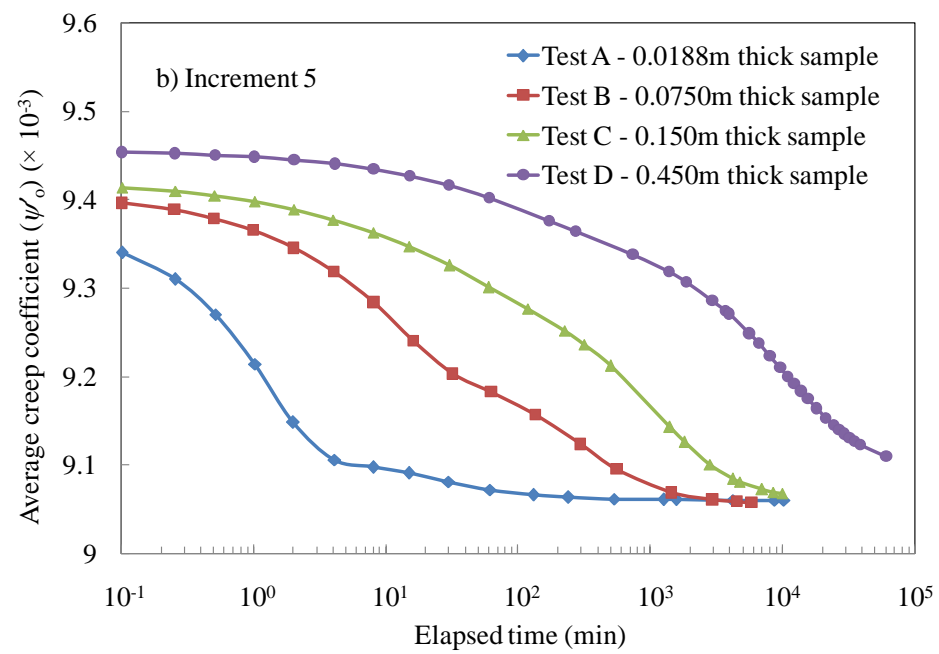

(b)

Fig. 14 The average creep coefficient $\psi_{o}^{\prime}$ of four different thickness samples of Drammen Clay during: (a) Increment 4; and (b) Increment 5 
Table 4 Model parameters for Drammen Clay obtained adopting TRRLS approach and the linear EVP model proposed by Yin and Graham (1989)

\begin{tabular}{|c|c|c|c|c|}
\hline \multicolumn{3}{|c|}{ Model parameters } & \multirow{2}{*}{$\begin{array}{c}\text { TRRLS method } \\
0.0158\end{array}$} & \multirow{2}{*}{$\begin{array}{c}\text { Linear EVP model } \\
0.004\end{array}$} \\
\hline Instant time-line & & & & \\
\hline \multirow{2}{*}{ Reference time-line } & \multicolumn{2}{|c|}{$\lambda / V$} & 0.17 & 0.158 \\
\hline & \multicolumn{2}{|c|}{$\sigma_{z o}^{\prime}(\mathrm{kPa})$} & 101.71 & 79.2 \\
\hline \multirow{3}{*}{ Equivalent time-line } & \multicolumn{2}{|c|}{$t_{o}(\min )$} & 1 & 40 \\
\hline & $\varepsilon_{l m}^{v p}$ & $\begin{array}{l}a \\
b\end{array}$ & $\begin{array}{c}0.6 \\
1 \times 10^{-6}\end{array}$ & NA \\
\hline & $\psi_{o}^{\prime}$ & $\begin{array}{l}c \\
d\end{array}$ & $\begin{array}{c}0.0134 \\
8.78 \times 10^{-4}\end{array}$ & 0.007 \\
\hline
\end{tabular}

disparities between the predicted and measured values in early stages as shown in Figs. 10(b), 11(b), 12(b) and 13(b)-(c). The phenomenon that the excess pore water pressure in a consolidation test reaches its maximum value (usually less than the applied stress increment), has been observed and discussed in several studies (Crawford 1964, Robinson 1999, Sonpal and Katti 1973, Whitman et al. 1961). The stiffness of the pore water pressure measurement device was considered as the reason causing the difference between the maximum pore water pressure and the applied stress increment. The stiffness of the pore water pressure measurement system may allow a partial drainage of pore water from the base of the soil sample (Whitman et al. 1961, Sonpal and Katti 1973, Robinson 1999). Charlie (2000) discussed that during the consolidation test the water from the soil can flow into or out of the measurement system, resulting in the change of the drainage condition of the impervious base of the soil sample.

Fig. 14 reports the average creep coefficient $\left(\psi_{o}^{\prime}\right)$ of Increments 4 and 5 of four samples of Tests A to D. As shown in Fig. 14, the initial values of $\psi_{o}^{\prime}$ of four samples are different, since the initial effective stress values of these four tests are slightly different. Since $\psi_{o}^{\prime}$ decreases with the increase of the effective stress, $\psi^{\prime}{ }_{o}$ also decreases with time during the dissipation of the excess pore water pressure, and remains almost constant after the required effective stress level (i.e., the dissipation of the excess pore water pressure completes) reaches. The thicker sample has a higher value of $\psi_{o}^{\prime}$ at any point of time, since the effective stress increases much slower compared to the thinner samples. For example, for Increment 4 in Fig. 14(a), $\psi_{o}^{\prime}$ of the $0.02 \mathrm{~m}$ thick sample starts decreasing and keeps constant after 10 minutes, while $\psi^{\prime}{ }_{o}$ of the thicker soil samples take longer time to reach a constant value. The samples in Test C and D as observed in Figs. 12(b) and 13(b)-(c) have not reached the end of the excess pore water pressure dissipation yet, thus the corresponding values of $\psi^{\prime}{ }_{o}$ continue to decrease. Additionally, $\psi^{\prime}{ }_{o}$ decreases as the effective stress increases; thus, $\psi^{\prime}{ }_{o}$ of Increment 4 is higher than $\psi_{o}^{\prime}$ value of Increment 5. For Drammen Clay, the value of the coefficient $b$ of the relationship equation of the creep strain limit $\varepsilon_{l m}^{v p}$ with the effective stress is negligibly small compared to the coefficient $a$ reported in Table 4 . Therefore, the creep strain limit $\varepsilon_{l m}^{v p}$ can be considered as constant for the reported case, since its variation with the effective stress is insignificant.

The variations of $\psi_{o}^{\prime}$ and $\varepsilon_{l m}^{v p}$ with time result in the variation of the creep parameter $(\psi / V)$. Fig. 15 illustrates the change of the average creep parameters with time. The average creep parameter is calculated as the average of the values of the whole layer, which is by the same manner of calculating the average vertical strain. The maximum values of $\psi / V$ are observed to 
decrease against the increase of the soil sample thicknesses. After increasing to the maximum values, the average creep parameters $(\psi / V)$ tend to decrease with time, since $\psi / V$ is not only stress dependent but also time dependent. The creep parameter is influenced not only by the creep strain limit and the creep coefficient, but also by the equivalent time $t_{e}$. Since during the early stage of loading, the creep strain limit and creep coefficient continuously decrease with the increase of the effective stress, the increase of the creep parameter is due to the decrease of the equivalent time $t_{e}$.

Fig. 16 shows the variation of the average creep strain rate of Increment 4 and Increment 5 for four different thickness soil samples. During Increment 4 (Fig. 16(a)), the thickest soil sample

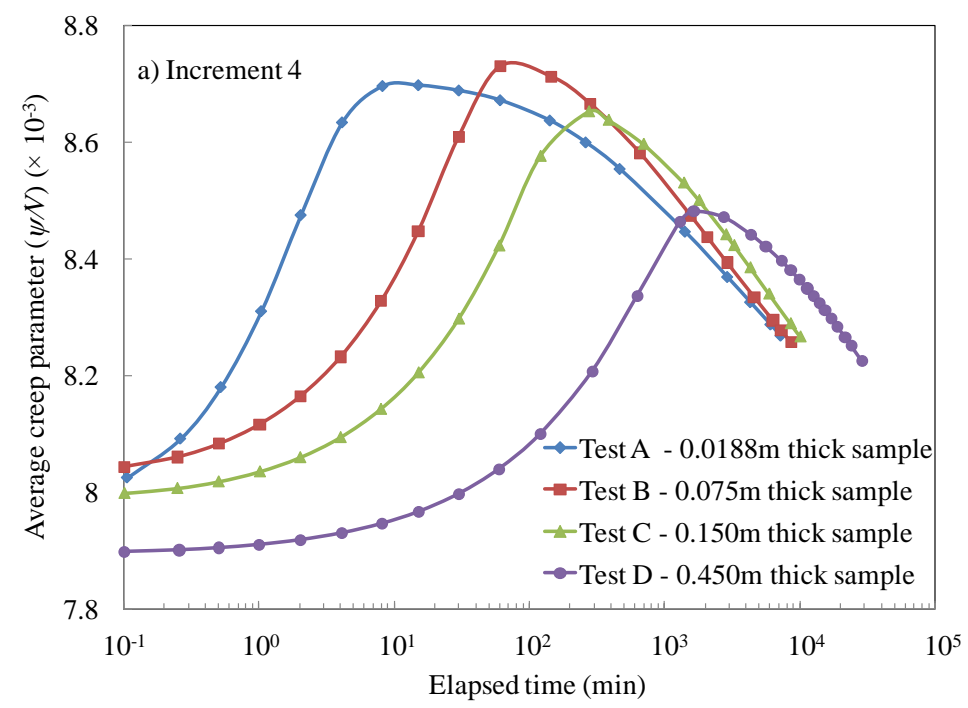

(a)

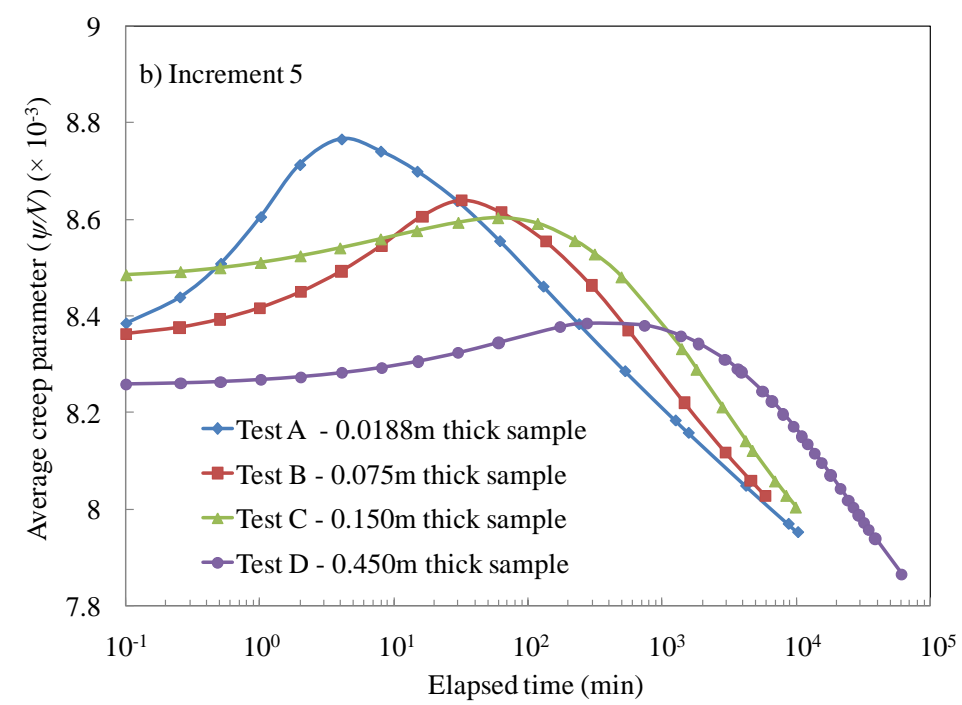

(b)

Fig. 15 The average creep parameter $\psi / V$ of four different thickness samples of Drammen Clay during (a) Increment 4; and (b) Increment 5 


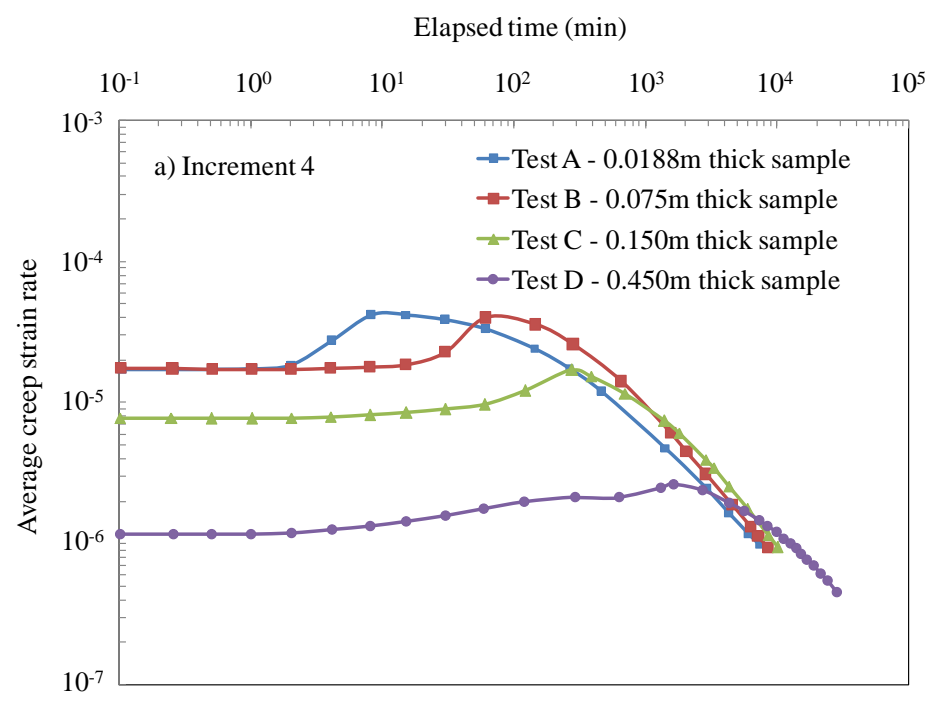

(a)

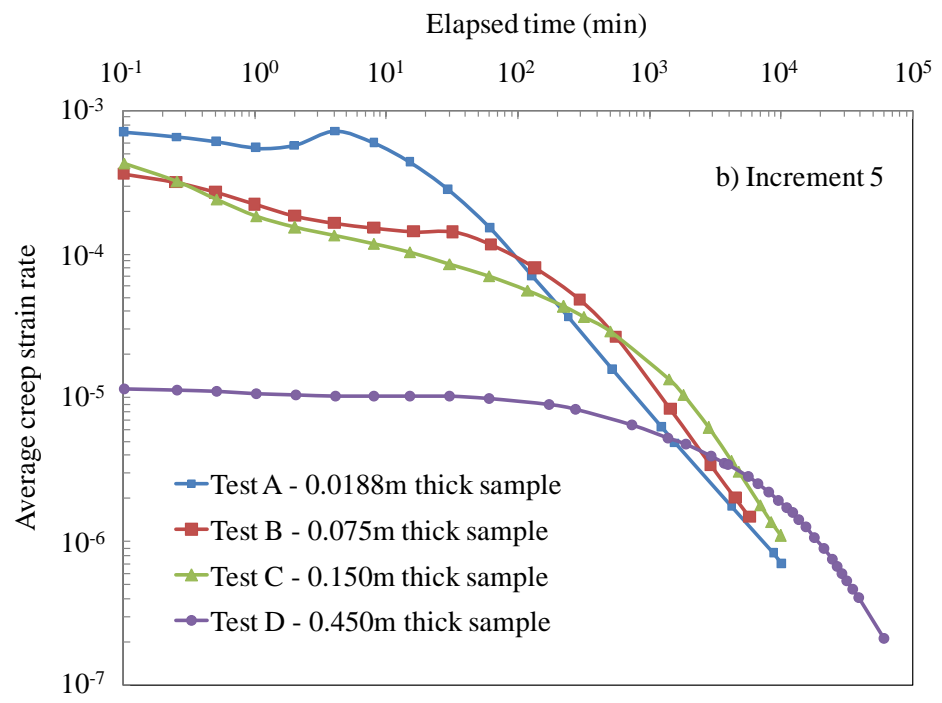

(b)

Fig. 16 The average creep strain rate $\dot{\varepsilon}^{v p}$ of four different thickness samples of Drammen Clay during (a) Increment 4 and (b) Increment 5

of Test $\mathrm{D}$ has the lowest average creep strain rate, and the average creep strain rate increases with the increases of the soil specimen thickness. It is also denoted that the average creep strain rates seem to remain constant during the early stages of the stress increment. Therefore, the early time of the stress increment (Increment 4), the compression induced by the elastic behaviour is more dominant, compared with the compression induced by creep, since Increment 4 is the transition from the overconsolidation range to the normal consolidation range (Berre and Iversen 1972). Gradually, with the increase in effective stresses beyonds the preconsolidation pressure, the creep contribution becomes more remarkable. 
It should be noted in the TRRLS approach the model parameters especially the creep strain limit $\left(\varepsilon_{l m}^{v p}\right)$ and the creep coefficient $\left(\psi_{o}^{\prime}\right)$ can be estimated with two stress increments. However, the conventional approach requires at least three creep tests with long loading time (at least one week for each stage) to predict the non-linear relationship between $\varepsilon_{l m}^{v p}$ and $\psi^{\prime}{ }_{o}$ with effective stresses (Yin 1999).

By adopting TRRLS approach, the model parameters can be obtained by employing the data points during the pore pressure dissipation. Moreover, the variations of the excess pore water pressure with time can be predicted with good agreement with the measurements. In summary, the current method adopting the finite difference method and TRRLS can be a feasible tool to analyse and predict the stress-strain-time relationship of soft soils.

In order to apply the proposed method to the field conditions, the finite difference solution should include the variations of the overburden effective stress, the applied stress intensity, the initial void ratio, the initial strain, as well as the preconsolidation pressure with depth. Moreover, several time-dependent settlement data measured at different depths would be required to obtain the model parameters for layered soils. In other words, for stratified soil deposit, settlement plates and markers should be installed and monitored at several depths to be used in back calculation process. Since the number of the data points must be more than the number of the model parameters, the more settlement plates and markers are available, the higher accuracy of the optimisation can be achieved. Additionally, the proposed method can adopt the measurement data from the early stages of loading to employ in the optimisation process without the requirement of long-term test measurements. Thus, the proposed method is applicable to the field measurement to back calculate the model parameters.

\section{Conclusions}

In this study, a non-linear elastic viscoplastic (EVP) model has been coupled with the theory of one dimensional consolidation in order to improve the prediction of time dependent stress-strain behaviour of soft soils. Implementing the EVP model developed by Yin (1999) in this study, the time parameter $t_{o}$ is adopted as a unit of time, while the stress and time dependent creep strain limits and creep coefficient are incorporated. A Crank-Nicolson finite difference solution has been applied to solve the coupled equations of the EVP model and the consolidation theory. Additionally, a model parameter determination method is introduced to define several model parameters simultaneously. This developed method is based on the trust-region reflective least square algorithm (TRRLS) in association with the finite difference solution. In order to assess the competence of the finite difference solution and TRRLS approach, two case studies have been analysed. In Case Study 1, TRRLS approach has been employed to determine a set of model parameters of Hong Kong Marine Clay using the experimental measurement of a multiple stage loading test. The model parameters by TRRLS approach results in good agreement between the prediction and laboratory measurements. Then, the settlement and the variation of excess pore water pressure of five soil specimens of different thicknesses have been calculated using the finite difference solution. It was observed that the thickness of the soil deposit has significant influence on the long-term settlement pattern as well as the response of the excess pore water pressure. The thicker the soil layer, the more delayed time the dissipation of excess pore water pressure at the base endures. That also means the more delayed compression takes place during the period of excess pore water pressure dissipation for the thicker specimens. Based on the predicted average 
strain of different soil sample thicknesses, the average vertical strain, when the excess pore water pressure dissipation process is almost completed, increases with the increase of the soil layer thickness.

In Case Study 2, the well-known laboratory tests of different thickness samples of Drammen Clay. TRRLS approach has been employed for validation of the developed method. TRRLS approach has been applied to obtain the model parameters of Drammen Clay from the thinnest soil specimen, and the finite difference solution has been used to predict the settlement and excess pore water pressure of the thicker specimens. The calculated results of the settlement and excess pore water pressure are in good agreement with the laboratory measurements. Despite the discrepancies of initial values of excess pore water pressure, the variation patterns of the excess pore water pressure are well predicted. It can be concluded that TRRLS approach allows the data collected during the excess pore water pressure dissipation to be utilised to determine the EVP model parameters capturing the elastic, plastic and viscous behaviours. The unit value of $t_{o}$ can be adopted to avoid the arbitrary selection of this model parameter. The settlement data obtained during the traditional primary consolidation stage (while the excess pore water pressure is being dissipated) can be utilised to obtain the visco-plastic model parameters. It should be noted that the capacity of TRRLS approach combined with the finite difference solution can be verified further, while the variation of the initial void ratio and the initial effective stresses with depth are considered for thick in situ clay layers. The developed method can be utilised to back-calculate the non-linear EVP model parameters in the field based on time-dependent settlement plate and piezometer readings.

\section{References}

Andersen, K.H., Rosenbrand, W.F., Brown, S.F. and Pool, J.H. (1980), “Cyclic and static laboratory tests on Drammen clay", J. Geotech. Eng. Div., 106(5), 499-529.

Azari, B., Fatahi, B. and Khabbaz, H. (2014), "Assessment of the elastic-viscoplastic behavior of soft soils improved with vertical drains capturing reduced shear strength of a disturbed zone", Int. J. Geomech. DOI: 10.1061/(ASCE)GM.1943-5622.0000448, B4014001.

Berre, T. and Iversen, K. (1972), "Oedometer tests with different specimen heights on a clay exhibiting large secondary compression”, Geotechnique, 22(1), 53-70.

Bjerrum, L. (1967), "Engineering geology of Norwegian normally-consolidated marine clays as related to settlements of buildings", Geotechnique, 17(2), 81-118.

Charlie, W. (2000), "Discussion on "Consolidation analysis with pore water pressure measurements"", Geotechnique, 50(5), 607-608.

Chen, W., De Kee, D. and Kaloni, P.N. (2003), Advanced Mathematics for Engineering and Science, World Scientific, Singapore.

Coleman, T.F. and Li, Y. (1996), “An interior trust region approach for nonlinear minimization subject to bounds", SIAM J. Optimization, 6(2), 418-445.

Conn, A.R., Scheinberg, K. and Vicente, L.N. (2009), Introduction to Derivative-Free Optimization, Society for Industrial and Applied Mathematics, PA, USA.

Cooreman, S., Lecompte, D., Sol, H., Vantomme, J. and Debruyne, D. (2007), "Elasto-plastic material parameter identification by inverse methods: Calculation of the sensitivity matrix", Int. J. Solid. Struct., 44(13), 4329-4341.

Crank, J. and Nicolson, P. (1947), “A practical method for numerical evaluation of solutions of partial differential equations of the heat-conduction type", Mathematical Proceedings of the Cambridge Philosophical Society, 43(1), 50-67.

Crawford, C.B. (1964), "Interpretation of the consolidation test", J. Soil Mech. Found. Eng. Div., 90(5), 
87-102.

Degago, S.A., Grimstad, G., Jostad, H.P. and Nordal, S. (2009), "The non-uniqueness of the end-of-primary (EOP) void ratio effective stress relationship", Proceedings of the 17th International Conference on Soil Mechanics and Geotechnical Engineering, Alexandria, Egypt, October, pp. 324-327.

Fatahi, B. and Tabatabaiefar, S. (2014), "Fully nonlinear versus equivalent linear computation method for seismic analysis of midrise buildings on soft soils", Int. J. Geomech., 14(4), 04014016. DOI: 10.1061/(ASCE)GM.1943-5622.0000354

Fatahi, B., Le, T.M., Le, M.Q. and Khabbaz, H. (2012), "Soil creep effects on ground lateral deformation and pore water pressure under embankments", Geomech. Geoeng., 8(2), 107-124.

DOI: $10.1080 / 17486025.2012 .727037$

Floudas, C.A. and Pardalos, P.M. (2008), Encyclopedia of Optimization, Springer, New York, NY, USA.

Geletu, A. (2007), "Solving optimization problems using the Matlab Optimization Toolbox - A Tutorial", TU-Ilmenau, Fakultat fur Mathematik und Naturwissenschaften.

Gnanendran, C., Manivannan, G. and Lo, S.-C. (2006), "Influence of using a creep, rate, or an elastoplastic model for predicting the behaviour of embankments on soft soils", Can. Geotech. J., 43(2), 134-154.

Gould, N., Orban, D. and Toint, P. (2005), "Numerical methods for large-scale nonlinear optimization", Acta Numerica, 14(1), 299-361.

Graham, J. and Yin, J.H. (2001), "On the time-dependent behaviour of soft soils", Proceedings of the 3rd International Conference on Soft Soil Engineering, Hong Kong, December, pp. 13-24.

Grasselli, M. and Pelinovsky, D. (2008), Numerical Mathematics, Jones and Bartlett Publishers, Sudbury, MA, USA.

Guven, N. (1992), "Molecular aspects of clay-water interactions", In: Clay-water Interface and its Rheological Implications (N. Guven and R.M. Pollastro Eds.), The Clay Minerals Society.

Ho, L., Fatahi, B. and Khabbaz, H. (2014), "Analytical solution for one-dimensional consolidation of unsaturated soils using eigenfunction expansion method", Int. J. Numer. Anal. Method. Geomech., 38(10), 1058-1077.

Hokmabadi, A.S., Fatahi, B. and Samali, B. (2014), "Assessment of soil-pile-structure interaction influencing seismic response of mid-rise buildings sitting on floating pile foundations", Comput. Geotech., 55(0), 172-186. http://dx.doi.org/10.1016/j.compgeo.2013.08.011

Jamiolkowski, M., Ladd, C., Germaine, J. and Lancellotta, R. (1985), "New developments in field and laboratory testing of soils", Proceedings of the 11th International Conference on Soil Mechanics and Foundation Engineering, San Francisco, CA, USA, August, pp. 57-153.

Kaloni, P.N., Chen, W. and De Kee, D. (2003), Advanced Mathematics for Engineering and Science, World Scientific, Singapore; River Edge, NJ, USA.

Karim, M.R. and Gnanendran, C. (2014), "Review of constitutive models for describing the time dependent behaviour of soft clays", Geomech. Geoeng., 9(1), 36-51.

Lambe, T.S. and Whitman, R (1969), Soil Mechanics, John Wiley \& Sons, Inc., New York, NY, USA.

Le, T.M., Fatahi, B. and Khabbaz, H. (2012), "Viscous behaviour of soft clay and inducing factors", Geotech. Geol. Eng., 30(5), 1069-1083.

Le, T.M., Fatahi, B. and Khabbaz, H. (2015), "Numerical optimisation to obtain elastic viscoplastic model parameters for soft clay", Int. J. Plast., 65, 1-21.

Leroueil, S., Kabbaj, M., Tavenas, F. and Bouchard, R. (1985), "Stress-strain-strain rate relation for the compressibility of sensitive natural clays", Geotechnique, 35(2), 159-180.

Mesri, G., Febres-Cordero, E., Shields, D.R. and Castro, A. (1981), "Shear stress-strain-time behaviour of clays", Geotechnique, 31(4), 537-552.

Murty, K.G. (2010), Optimization for Decision Making: Linear and Quadratic Models, Springer Science and Bussiness Media, New York, NY, USA.

Nash, D. (2001), "Modelling the effects of surcharge to reduce long term settlement of reclamations over soft clays: A numerical case study", Soil. Found., 41(5), 1-13.

Nguyen, L.D., Fatahi, B. and Khabbaz, H. (2014), "A constitutive model for cemented clays capturing cementation degradation”, Int. J. Plast., 56(1), 1-18. 
Raj, P.P. (2008), Soil Mechanics \& Foundation Engineering, Dorling Kindersley, London, UK.

Robinson, R. (1999), "Consolidation analysis with pore water pressure measurements", Geotechnique, 49(1), 127-132.

Sonpal, R. and Katti, R. (1973), "Consolidation - An analysis with pore pressure measurements", Proceedings of the 8th ICSMFE (Volume 1.2), Moscow, Russia, pp. 385-388.

Strikwerda, J. (2007), Finite Difference Schemes and Partial Differential Equations, Society for Industrial and Applied Mathematics, Pacific Grove, CA, USA.

Tabatabaiefar, S.H.R., Fatahi, B. and Samali, B. (2012), "Seismic behavior of building frames considering dynamic soil-structure interaction”, Int. J. Geomech., 13(4), 409-420.

Tabatabaiefar, S.H.R., Fatahi, B. and Samali, B. (2013), "Lateral seismic response of building frames considering dynamic soil-structure interaction effects", Struct. Eng. Mech., Int. J., 45(3), 311-321.

Terzaghi, K. (1941), "Undisturbed clay samples and undisturbed clays", J. Boston Soc. Civil Eng., 28(3), 45-65.

Vermeer, P. and Neher, H. (1999), "A soft soil model that accounts for creep", Proceedings of the International Symposium Beyond 2000 in Computational Geotechnics, Amsterdam, Netherlands, March, pp. 249-261.

Watabe, Y., Udaka, K., Nakatani, Y. and Leroueil, S. (2012), "Long-term consolidation behavior interpreted with isotache concept for worldwide clays", Soil. Found., 52(3), 449-464. http://dx.doi.org/10.1016/j.sandf.2012.05.005

Whitman, R., Richardson, A. and Healy, K. (1961), "Time-lags in pore pressure measurements", Proceedings of the 5th International Conference on Soil Mechanic and Foundation Engineering, Paris, France, July, pp. 407-411.

Yin, J.H. (1999), "Non-linear creep of soils in oedometer tests", Geotechnique, 49(5), 699-707.

Yin, J.H. and Graham, J. (1989), "Viscous-elastic-plastic modelling of one-dimensional time-dependent behaviour of clays", Can. Geotech. J., 26(2), 199-209.

Yin, J.H. and Graham, J. (1994), "Equivalent times and one-dimensional elastic viscoplastic modelling of time-dependent stress-strain behaviour of clays", Can. Geotech. J., 31(1), 42-52.

Yin, J.H. and Graham, J. (1996), "Elastic visco-plastic modelling of one-dimensional consolidation", Geotechnique, 46(3), 515-527.

Yin, J.H. and Zhu, J.G. (1999), "Measured and predicted time-dependent stress-strain behaviour of Hong Kong marine deposits", Can. Geotech. J., 36(4), 760-766.

Yuan, Y. (2011), "Gradient methods for large scale convex quadratic functions", In: Optimization and Regularization for Computational Inverse Problems and Applications, Springer, pp. 141-155.

Yun, G.J. and Shang, S. (2011), "A self-optimizing inverse analysis method for estimation of cyclic elastoplasticity model parameters”, Int. J. Plast., 27(4), 576-595.

$C C$ 


\section{Appendix}

Crank-Nicolson finite difference scheme is introduced to solve the partial differential Eqs. 8(a)-(b). The Crank-Nicolson calculation procedure is based on central difference approximate in space and the trapezoidal rule in time (Crank and Nicolson 1947). Crank-Nicolson method is fully implicit and unconditionally stable. In other words, the time step is not restricted, and can be larger compared to other explicit methods (Kaloni et al. 2003). Fig. A1 shows the general conception of the finite difference grids with the coordinator axes for depth and time. The variation in the depth $z$ is presented by the subscript $i$ starting from 1 to $n$, and the subscript $j$ stands for the variation in the time coordinator. A coordinator $(i, j)$ includes the subscript $i$ for depth followed by the subscript $j$ for time. To acquire the numerical solutions, the partial differential equations are implemented into a MATLAB code. It is noted that the coordinators begin with 1 instead of 0 for the programming simplification.

By defining $r(i, j)=\left(c_{v}\right)_{(i, j)} \frac{\Delta t}{2(\Delta z)^{2}}$ and $h(i, j)=\Delta t \frac{1}{\left(m_{v}\right)_{(i, j)}}\left(g\left(\varepsilon_{z}, \sigma_{z}^{\prime}\right)\right)$ and applying the CrankNicolson scheme, the partial differential Eqs. (8a) and (8b) are derived as follows

$$
\begin{gathered}
-0.5 r_{(i, j)} u_{(i-1, j+1)}+\left(1+r_{(i, j)}\right) u_{(i, j+1)}-0.5 r_{(i, j)} u_{(i+1, j+1)} \\
=0.5 r_{(i, j)} u_{(i-1, j)}+\left(1-r_{(i, j)}\right) u_{(i, j)}+0.5 r_{(i, j)} u_{(i+1, j)}+h_{(i, j)} \\
\left(\varepsilon_{z}\right)_{(i, j+1)}=\left(\varepsilon_{z}\right)_{(i, j)}-\left(m_{v}\right)_{(i, j)}\left(u_{(i, j+1)}-u_{(i, j)}\right)+\Delta t\left(g\left(\varepsilon_{z}, \sigma \sigma_{z}\right)\right)_{(i, j)}
\end{gathered}
$$

where, $i=2,3, \ldots, n$, and $j=1,2,3, \ldots, m-1$, and $\Delta z$ and $\Delta t$ are the increments of depth and time, respectively. $\Delta z$ is kept constant, while $\Delta t$ can change during the calculation process. Since Crank-Nicolson finite difference scheme is unconditionally stable and ensures the stability and convergence, the adopted time steps were sufficient to capture the variations of stress-strain with time.

The two types of boundary conditions used in this paper include one-way drainage via pervious top layer (Fig. A1(a)) and two-way drainage (Fig. A1(b)), with following conditions:

- At $z=0, u_{(1, j)}=0$ for $j=1$ to $m$

- At $z=H_{o}$, for the one-way drainage condition, $\frac{\partial u}{\partial z}=0$. It is called derivative boundary condition or Neumann boundary condition. Applying the central difference in space for the derivative equation can lead to a better accuracy for solution (Kaloni et al. 2003). In order to implement the boundary conditions into the Crank-Nicolson scheme, a fictitious layer is added below the undrained boundary. The fictitious layer has $i$ equal to $n+1$.

$$
\frac{u_{(n+1, j)}-u_{(n-1, j)}}{2 \Delta z}=0
$$

Thus, $u_{(n+1, j)}-u_{(n-1, j)}$ for $j=1$ to $m$

At $z=H_{o}$, for the two-way drainage condition, $u_{(n, j)}=0$ for $j=1$ to $\mathrm{m}$ 
By applying Crank-Nicolson procedure, the initial values including $\sigma_{z(i, 1)}, u_{(i, 1)}$ and $\varepsilon_{z(i, 1)}$ are required, and the initial effective stresses are calculated using $\sigma_{z(i, 1)}^{\prime}=\sigma_{z(i, 1)}-u_{(i, 1)}$. In addition to the key Eqs. A1(a)-(b), Eqs. A3(a)-(e) are incorporated to compute the effective stress and time dependent parameters in the calculation process. Eqs. A3(a)-(b) define the stress dependent creep strain limit and the creep coefficient with respect to depth and time. In these two equations, $a, b, c$, and $d$ are four constant model parameters obtained by curve fitting of the data points. Eqs. (A3c), A3(d)-(e) determine the coefficient of volume compressibility $m_{v}$, the permeability $k$ and the consolidation coefficient $c_{v}$ with respect to depth and time, respectively. It should be noted that the set coefficient of Eqs. A3(a)-(e) is recalculated at each time step.

$$
\begin{gathered}
\left(m_{v}\right)_{(i, j)}=\frac{\kappa}{V} \frac{1}{\left(\sigma_{z}^{\prime}\right)_{(i, j)}} \\
(k)_{(i, j)}=k_{0} \times 10 \frac{-\left(\varepsilon_{z}\right)_{(i, j)}\left(1+e_{o}\right)}{c_{k}} \\
\left(c_{v}\right)_{(i, j)}=\frac{(k)_{(i, j)}}{\gamma_{w}\left(m_{v}\right)_{(i, j)}}
\end{gathered}
$$

where, $i=1,3, \ldots, n$, and $j=1,2,3, \ldots, m-1$.

Using the initial values, boundary conditions and Eqs. A1(a)-(b), a system of equations involving a tridiagonal square matrix (Eqs. A4) is formed to solve for vertical effective stresses and strains. Eq. (A4a) is for one-way drainage cases, while Eq. (A4a) is used to solve the two-way drainage cases. For the one-way drainage condition, the matrix system has $n-1$ equations to solve for $n-1$ unknown $u_{(i, j+l)}$. On the other hand, for two-way drainage cases, the matrix system of $(n-2)$ equations is ready to solve for $(n-2)$ unknown $u_{(i, j+1)}$. For the ease of observation, $r$ in the tridiagonal system stands for $r_{(i, j)}$.

$$
\begin{aligned}
& {\left[\begin{array}{cccccc}
1+r & -0.5 r & 0 & \cdot & 0 & 0 \\
-0.5 r & 1+r & -0.5 r & \cdot & 0 & 0 \\
0 & -0.5 r & 1+r & \cdot & 0 & 0 \\
\cdot & \cdot & \cdot & \cdot & \cdot & \cdot \\
0 & 0 & 0 & \cdot & 1+r & -0.5 r \\
0 & 0 & 0 & \cdot & -r & 1+r
\end{array}\right]\left[\begin{array}{c}
u_{2} \\
u_{3} \\
u_{4} \\
\cdot \\
u_{n-1} \\
u_{n}
\end{array}\right]^{j+1}} \\
& =\left[\begin{array}{cccccc}
1-r & 0.5 r & 0 & \cdot & 0 & 0 \\
0.5 r & 1-r & 0.5 r & \cdot & 0 & 0 \\
0 & 0.5 r & 1-r & \cdot & 0 & 0 \\
\cdot & \cdot & \cdot & \cdot & \cdot & \cdot \\
0 & 0 & 0 & \cdot & 1-r & 0.5 r \\
0 & 0 & 0 & \cdot & r & 1-r
\end{array}\right]\left[\begin{array}{c}
u_{2} \\
u_{3} \\
u_{4} \\
\cdot \\
u_{n-1} \\
u_{n}
\end{array}\right]+\left[\begin{array}{c}
h_{2} \\
h_{3} \\
h_{4} \\
\cdot \\
h_{n-1} \\
h_{n}
\end{array}\right]^{j}
\end{aligned}
$$




$$
\begin{aligned}
& {\left[\begin{array}{cccccc}
1+r & -0.5 r & 0 & \cdot & 0 & 0 \\
-0.5 r & 1+r & -0.5 r & \cdot & 0 & 0 \\
0 & -0.5 r & 1+r & \cdot & 0 & 0 \\
\cdot & \cdot & \cdot & \cdot & \cdot & \cdot \\
0 & 0 & 0 & \cdot & 1+r & -0.5 r \\
0 & 0 & 0 & \cdot & -0.5 r & 1+r
\end{array}\right]\left[\begin{array}{c}
u_{2} \\
u_{3} \\
u_{4} \\
\cdot \\
u_{n-2} \\
u_{n-1}
\end{array}\right]^{j+1}} \\
& =\left[\begin{array}{cccccc}
1-r & 0.5 r & 0 & \cdot & 0 & 0 \\
0.5 r & 1-r & 0.5 r & \cdot & 0 & 0 \\
0 & 0.5 r & 1-r & \cdot & 0 & 0 \\
\cdot & \cdot & \cdot & \cdot & \cdot & \cdot \\
0 & 0 & 0 & \cdot & 1-r & 0.5 r \\
0 & 0 & 0 & \cdot & 0.5 r & 1-r
\end{array}\right]\left[\begin{array}{c}
u_{2} \\
u_{3} \\
u_{4} \\
\cdot \\
u_{n-2} \\
u_{n-1}
\end{array}\right]^{j}+\left[\begin{array}{c}
h_{2} \\
h_{3} \\
h_{4} \\
\cdot \\
h_{n-2} \\
h_{n-1}
\end{array}\right]^{j}
\end{aligned}
$$

Substituting the value of $u_{(i, j+l)}$ into Eq. (A1b) derives the value of $\left(\varepsilon_{z}\right)_{(i, j+l)}$. The ground surface settlement (at $z=0$ ) at time $t$ is derived using Eq. (A5) adopting the vertical strains at time $t$.

$$
S_{t}=\int_{z=0}^{z=H_{o}}\left(\varepsilon_{z}\right)_{t} d z
$$

Using an approximate solution for Eq. (A5), the ground surface settlement at time $\mathrm{t}\left(S_{t}\right)$ and the average vertical strain at time $t$ (or at each time step $j$ ) $\left(\varepsilon_{z_{\_} \text {ave }}\right)_{t}$ are computed using Eqs. (A6) and (A7), respectively.

$$
\begin{gathered}
S_{t}=S_{j}=\left[0.5\left(\left(\varepsilon_{z}\right)_{(1, j)}+\left(\varepsilon_{z}\right)_{(n, j)}\right)+\sum_{i=2}^{i=n-1}\left(\varepsilon_{z}\right)_{(i, j)}\right] \Delta z \\
\left(\varepsilon_{z_{-} \text {ave }}\right)_{t}=\left(\varepsilon_{z_{-} \text {ave }}\right)_{j}=\frac{S_{j}}{H_{o}}
\end{gathered}
$$

where, $H_{o}$ is the initial thickness of the soil layer. 